\title{
WestVirginiaUniversity
}

THE RESEARCH REPOSITORY @ WVU

Graduate Theses, Dissertations, and Problem Reports

2005

\section{Perceptions of mothers labeled adolescent or adult and their infants}

Nichole L. Elliott

West Virginia University

Follow this and additional works at: https://researchrepository.wvu.edu/etd

\section{Recommended Citation}

Elliott, Nichole L., "Perceptions of mothers labeled adolescent or adult and their infants" (2005). Graduate Theses, Dissertations, and Problem Reports. 2174.

https://researchrepository.wvu.edu/etd/2174

This Thesis is protected by copyright and/or related rights. It has been brought to you by the The Research Repository @ WVU with permission from the rights-holder(s). You are free to use this Thesis in any way that is permitted by the copyright and related rights legislation that applies to your use. For other uses you must obtain permission from the rights-holder(s) directly, unless additional rights are indicated by a Creative Commons license in the record and/ or on the work itself. This Thesis has been accepted for inclusion in WVU Graduate Theses, Dissertations, and Problem Reports collection by an authorized administrator of The Research Repository @ WVU. For more information, please contact researchrepository@mail.wvu.edu. 
Perceptions of Mothers Labeled Adolescent or Adult and Their Infants

Nichole L. Elliott

Thesis submitted to the Eberly College of Arts and Sciences at the West Virginia University in partial fulfillment of the requirements for the degree of

Master of Science in Life-span Developmental Psychology

Katherine Karraker, Ph.D., Chair

JoNell Strough, Ph.D.

Tracy Morris, Ph.D.

Department of Psychology

Morgantown, West Virginia

2005

Keywords: Adolescent Motherhood, Infants, Perceptions, Stereotypes 


\section{ABSTRACT \\ Perceptions of Mothers Labeled Adolescent or Adult and Their Infants}

Nichole L. Elliott

The aim of the current study was to examine how adolescent and/or unmarried mothers and their infants are perceived in comparison to adult and/or married mothers and their. Negative appraisals by others of adolescent and/or unmarried mothers and their infants may contribute to the difficulties they encounter. Psychology students viewed videotapes of adult, married mothers labeled as adolescent or adult and as unmarried or married interacting with their infants.

Participants were asked to rate the infants, the mothers and their interactions. Results show that there were cases in which those labeled adolescent and unmarried were seen less positively than those labeled adult and married. There were also instances of counterintuitive findings where ratings were lower for those labeled adult and married instead of adolescent and unmarried. This study provides evidence that perceptions and stereotypes can result in negative appraisals of adolescent or unmarried mothers and their infants, but also that there are situations where these mothers and their infants can exceed the expectations of others. 
Perceptions of Mothers and Infants iii Dedication

I would like to dedicate this project to my family, without whose support I could never reach my full potential, and to my fiancé, Dave Kang, who never fails to tell me how proud he is of me. 
Acknowledgements

I would like to thank all of those who helped and supported me during the last three years.

First, I would like to thank Dr. Katherine Karraker for her ideas, immense wealth of knowledge, and guidance that I needed to finish this project with great success.

Second, I would like to thank Marie Sorokin for her help with data collection and data entry; I couldn't have done it without you!

I would also like to thank all of my friends here at WVU for the moral and emotional support we all have for each other. Our continued friendship has made the stresses of graduate school worthwhile while we're still here.

Finally, I wish to acknowledge the alumni who donated to the Psychology Department's Alumni Fund, without which I would not have had the supplies necessary to carry out this project. 
Table of Contents

Title Page..................................................... i

Abstract............................................................ ii

Dedication..................................................... iii

Acknowledgements........................................... iv

Table of Contents........................................ v-vi

List of Tables............................................. vii

List of Figures................................................... vii

Chapter 1: Introduction........................................ 1

Infants and Children of Adolescent Mothers.................... 4

Characteristics of Adolescent Mothers........................ 7

Successful Adolescent Mothers............................... 9

Stigmatization of Adolescent Mothers...................... 12

Expectancy Confirmation................................. 14

Labeling Studies......................................... 15

Statement of the Problem.................................... 16

Research Questions and Hypotheses........................ 17

Method......................................................... 18

Participants............................................. 18

Stimuli............................................... 19

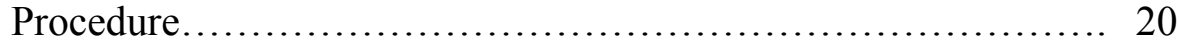

Measures.............................................. 21

Analysis Plan........................................... 23

Results.................................................. 25

Infant Rating Scales................................... 25

Mother Rating Scales...................................... 26

Infant Interaction Rating Scales.......................... 27

Mother Interaction Rating Scales........................ 28

Discussion................................................ 29

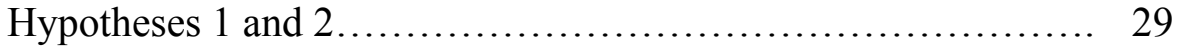

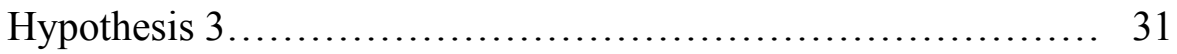




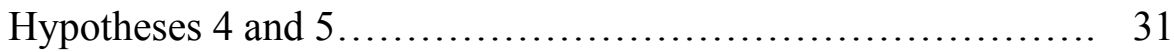

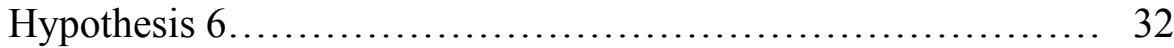

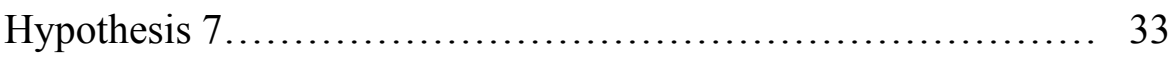

Implications......................................... 34

Limitations............................................. 35

Conclusions................................................. 38

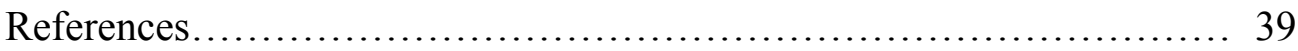

Appendices....................................................... 76

Appendix A: Instructions................................... 77

Appendix B: Vignettes.................................. 78

Appendix C: Infant Rating Scale................................................... 79

Appendix D: Mother Rating Scale........................... 81

Appendix E: Interaction Rating Scales...................... 83

Appendix F: Background Questionnaire..................... 85

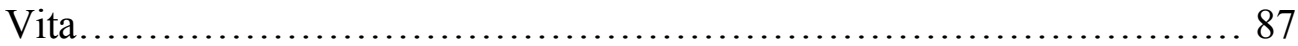


List of Tables

Table 1: Conditions.................................................... 45

Table 2: MANOVAs and ANOVAs for Infant Rating Scales............... 46

Table 3: Means, SDs, and t-values for IRS Univariate Effects.............. 47

Table 4: Means and SDs for Video Number Main Effects.................. 49

Table 5: MANOVAs and ANOVAs for Mother Rating Scales............. 50

Table 6: Means, SDs, and t-values for MRS Univariate Effects............ 52

Table 7: MANOVAs and ANOVAs for Infant Interaction Rating Scales... 53

Table 8: Means and SDs for IIRS Univariate Effects...................... 54

Table 9: MANOVAs and ANOVAs for Mother Interaction Rating Scales.. 55

Table 10: Means, SDs, and t-values for MIRS Univariate Effects........... 56

Table 11: F, Means, and SDs for Individual Items in IRS with Video...... 57

Table 12: F, Means, and SDs for Individual Items in MRS with Video.... 64

Table 13: F, Means, and SDs for Individual Items in MRS without Video.. 66

Table 14: F, Means, and SDs for Individual Items in IIRS with Video.... 71

Table 15: F, Means, and SDs for Individual Items in MIRS with Video... 73

Table 16: F, Means, and SDs for Individual Items in MIRS without Video. 74 
List of Figures

Figure 1: Other's negative expectations of adolescent mothers and the self-fulfilling prophecy....................................................... 
Perceptions of Mothers and Infants 1

Introduction

Although the rate of adolescent pregnancy in the United States has been declining since 1991, 45.9 out of every 1000 females between the ages of 15 and 19 gave birth in the year 2001 (MacDorman, Minino, Strobino, \& Guyer, 2002). The teen birth rate in the United States remains notably higher than the rates in other industrialized countries. Every year in the U.S., approximately $13 \%$ of all births are to mothers between the ages of 15 and 19 (Ventura, Martin, Curtin, \& Mathews 1999), with 80\% of births to adolescent women being out of wedlock in 1999 (Ventura \& Bachrach, 2000). Each year in the U.S. approximately $8 \%$ of adolescent women between the ages of 15 and 19 become pregnant and about $57 \%$ of these women give birth (Alan Guttmacher Institute, 2004a). Fifteen percent of African American adolescent women, 13\% of Hispanic adolescent women, and 7\% of Caucasian adolescent women between the ages of 15-19 become pregnant before the age of 20 (Alan Guttmacher Institute, 2004b). Almost 75\% of adolescent mothers go on welfare within 5 years of the birth of their first child (Annie E. Casey Foundation, 1998). All of these findings highlight the magnitude and prevalence of adolescent motherhood in the United States.

Studies have shown that adolescent mothers are often less competent caregivers than adult mothers and that the development of children of adolescent mothers is often negatively influenced by the circumstances in which they are raised. The aim of the current study is to learn how adolescent mothers and their infants are perceived by others in comparison to adult mothers and their infants. The development of negative perceptions is the first step in the longer process of expectancy confirmation. The perceptions others have of adolescent mothers may influence the way they interact with these mothers. For example, those individuals with negative perceptions of all adolescent mothers may also act negatively toward any adolescent mother with whom they come into contact. Throughout this paper mothers who had at least one child in their teenage years (up to 19 years of age) will be referred to as adolescent mothers and mothers who did not have their first child until adulthood (20 years or later) will be referred to as adult mothers.

Children born to adolescent mothers are often faced with many disadvantages throughout their lives as compared to most children of adult mothers. Infants of adolescent mothers have been found to produce fewer vocalizations and smile less at 4 months of age (Barratt \& Roach, 1995), to score lower on the Bayley Scales of Human Development at 8 months of age (Hardy, 
Welcher, \& Stanley, 1978), to be at a higher risk for social-emotional and intellectual problems as they grow older (Black et al., 2002; Hubbs-Tait, Osofsky, Hann, \& McDonald Culp, 1994; Sommer et al., 2000; Spieker, Larson, Lewis, Keller, \& Gilchrist, 1999), and to show more disruptive behaviors (Spieker et al.) than children born to adult mothers. Further, problem behaviors in young children, such as the abovementioned, are related to psychological maladjustment in adolescence and adulthood (Parker \& Asher, 1987). This finding indicates that, as children of adolescent mothers are at a greater risk for showing problem behaviors, they may also be more likely to have adjustment problems in adolescence and adulthood.

Many studies have shown that adolescent mothers are less verbally stimulating to their young children (Barratt \& Roach, 1995; Culp, Appelbaum, Osofsky, \& Levy, 1988), are more likely to be unhappy about their pregnancy (Culp et al.), are less responsive to their infants (Barratt \& Roach), are less sensitive to their infants (McAnarney, Lawrence, Ricciuti, Polley, \& Szilagyi, 1986), and are more likely to have unrealistic expectations for their infants' development (Karraker \& Evans, 1995; Price \& Gillingham, 2001; Tamis-Lemonda, Shannon, \& Spellmann, 2002; Vukelich \& Kliman, 1985 ) than are adult mothers. Individuals with negative perceptions of adolescent mothers can develop these perceptions through many different means, such as by reading published research findings, observing discussion by the media, interacting with adolescent mothers, communicating religious values, etc. Yet, no matter how the perceptions developed, people who have negative perceptions of adolescent mothers may act more negatively toward these mothers and their children as a result of their perceptions. Also, research findings that cast a negative light on adolescent motherhood perpetuate the negative perceptions that individuals may have about adolescent mothers.

The general consensus in the Unites States tends to be that adolescent parenthood has negative consequences for the adolescent mothers and their children, as well as society as a whole. In a Planned Parenthood poll taken in the late 1980 's, $95 \%$ of adults said that they thought adolescent parenthood was a large problem in the United States (Alan Guttmacher Institute, 1998). Likewise, in a 1996 survey taken by the Kaiser Family Foundation, 69\% of teenagers said they thought adolescent parenthood was a serious problem, with only $4 \%$ of teenagers saying they did not think it was a problem. Also, Hacker, Amare, Strunk, and Horst (2000) reported that, through a national survey, they found that fewer than $1 \%$ of sexually active teens under the age of 17 wanted to become pregnant during their teenage years. 
Surveys taken in the United States have shown that adults and teenagers alike see adolescent parenthood as a problem, yet we do not yet know the content of people's perceptions of adolescent mothers. One of the aims of this study is to determine how people view adolescent mothers and their infants. More specifically, our aims include finding whether or not adolescent mothers are seen as competent caregivers compared to adult mothers. Another aim is to determine if the development of infants born to adolescent mothers is thought to be normal in comparison to children of adult mothers. Research on these topics is important, as the beliefs people hold about adolescent mothers and their infants can have a large influence on how people act toward both these mothers and their children.

Adolescent pregnancy and parenthood can be thought of as a stigmatizing condition. A stigma is a devaluating attribute of a person, as deemed by the perceiver, which is linked to cultural and societal values (Goffman, 1963). Thus, those who are stigmatized have an undesirable characteristic that is seen as deviating from the norms of society. The apparent lack of research that addresses adolescent parenthood as a stigma suggests that adolescent pregnancy and parenthood are not traditionally thought of as stigmatizing conditions. Yet when looking at the negative effects that adolescent parenthood can have on adolescent mothers and their children, it is easy to conclude that adolescent mothers may be stigmatized. Stigmatization usually includes a belief in stereotypes. A stereotype is an oversimplified, homogeneous idea held by a person about another person's or group's attributes. People with the same stigma are thought to have similar negative attributes (Biernat \& Dovidio, 2000). In the case of adolescent mothers, for example, someone who has negative perceptions of adolescent mothers may classify any adolescent mother they meet as a poor caregiver, even though many of these mothers are actually competent caregivers.

Individuals who hold stereotypes about adolescent mothers and their infants may be more likely to look for behaviors that confirm their beliefs, while at the same time disregarding any behaviors that may contradict these beliefs, thus reinforcing their stereotypes (Darley \& Fazio, 1980). When a perceiver's expectations of a target person (the person with the stigma) affect the way the perceiver acts toward that target, this behavior may elicit the exact reaction the perceiver is expecting (Darley \& Fazio). When this phenomenon occurs, teenage mothers have very little chance of proving themselves to be capable and competent caregivers for their infants. For instance, in the case of adolescent mothers, when faced with perceivers' negative expectations of 
them and consequent negative behaviors toward them, adolescent mothers may begin to see themselves as ineffectual caregivers and begin to act in accordance with those negative expectations. This phenomenon is referred to as a self-fulfilling prophecy and the process by which a self-fulfilling prophecy occurs is termed expectancy confirmation.

Experimental labeling procedures have been applied to study the content and effects of stereotypes while at the same time reducing the chance that a participant will answer controversial questions in a socially desirable way. The labeling procedure generally entails labeling a non-deviant target as deviant (having an attribute that deviates from societal norms) and then asking participants to rate the target on a number of scales. A control condition, where non-deviant targets are labeled as non-deviant, is used for comparison. Participants often rate a deviant-labeled target more negatively than a non-deviant-labeled target. For example, Darley and Gross (1983) had participants in two groups watch an identical videotape of a child taking an exam; one group was told the girl was from a high socioeconomic background and the other group was told she was from a low socioeconomic background. Those who were told that the girl was from a high socioeconomic background rated her academic abilities as above average for her grade level whereas those who were told she was from a low socioeconomic background rated her abilities as below average.

In the following literature review, the common characteristics of adolescent mothers and their infants and children will be reviewed. These sections will provide the reader with an understanding of common negative attributes of adolescent mothers and their children, which may act as evidence as to why people may stereotype these mothers and their children. A discussion on stigma will follow, where links between the stigma of adolescent motherhood and expectancy confirmation will be proposed. These sections will present the reader with a better understanding of the effects that stigmatization may have on the stigmatized. Finally, studies that utilized labeling procedures as well as evidence for the effective use of these procedures will be discussed, as the current study will be carried out using an experimental labeling procedure.

\section{Literature Review}

\section{Infants and Children of Adolescent Mothers}

Children of incompetent adolescent parents can be negatively and enduringly affected by poor caregiving styles (Parker \& Asher, 1987). Hubbs-Tait and colleagues (1994) found that infants of Caucasian and African American mothers who had an insecure or disorganized 
Perceptions of Mothers and Infants 5

attachment to their mothers at 13 months of age had more internalizing and externalizing problems at 54 months of age than did infants with secure attachments to their mothers. Research has shown that there is a high degree of continuity between early problem behaviors and later maladjustment (Parker \& Asher, 1987). These studies offer some evidence that children with internalizing and externalizing behavior problems are at a greater risk for later maladjustment (Sroufe \& Rutter, 1984).

A young child's social competence serves as an important predictor of psychological adjustment in adulthood (Parker \& Asher, 1987). Hubbs-Tait and colleagues (1994) found that Caucasian and African American adolescent mothers' self-esteem, a topic that will be discussed in more depth below, is related to their young children's social competence. Adolescent mothers with low self-esteem are more likely to raise a child who is less socially competent than a child who is raised by an adolescent mother with higher self-esteem, which could further lead to behavior problems in childhood and psychological maladjustment in adulthood (Hubbs-Tait et al.).

Children who were born to adolescent mothers are at a greater risk for problems with social functioning (Hubbs-Tait et al., 1994), adaptive behaviors, and linguistic and emotional functioning (Sommer et al., 2000) than are children born to adult mothers. These children also show more disruptive behaviors than children born to adult mothers (Spieker et al., 1999). Sommer and colleagues found that, by the age of 3 , only $28 \%$ of children who were born to the African American and Caucasian adolescent mothers in their studies were within the normal range for cognitive development, socio-emotional maturity, and adaptive behavior. Thus, the $72 \%$ of children of adolescent mothers who did not fall into this normal range may show more problem behaviors, lag behind other children in school, and have more difficulty interacting with peers in a socially acceptable way.

Children born to adolescent mothers were found to experience more academic problems throughout their education. In Furstenberg, Brooks-Gunn, and Morgan's (1987) Baltimore study of 296 children born to African American adolescent mothers, 53\% had to be held back a grade for at least one year, making them over-represented in the population of those children who had to be held back. Being held back a grade sets a child behind his or her peers for the remainder of formal schooling, which can pose a risk to his or her self-esteem as it may make him or her feel less intelligent than children of the same age. 
Perceptions of Mothers and Infants 6

Sommer and colleagues (2000) found that there is a correlation between adolescent mothers' IQ and their children's intellectual functioning. Seventy-one percent of the women in this study were African American and 20\% were Caucasian. On average, the women came from low socioeconomic status and were found to have below average IQs $(\mathrm{M}=86.99, \mathrm{SD}=12.03)$. The mothers who had average or above average IQs provided more mental stimulation for their children than did mothers with low IQs. Although the link between mothers' and children's IQs can be partially accounted for by genetics, this evidence shows that mental stimulation may also be a factor in cognitive abilities. This finding could also help explain the findings from the Furstenberg and colleagues' (1987) study that showed that $53 \%$ of children of adolescent mothers in the study had to be held back a grade. If the average adolescent mother has belowaverage IQ and does not mentally stimulate her child, she may be putting her child at a disadvantage as compared to more mentally stimulating mothers. Sommer and colleagues use this process to help explain the findings from their aforementioned study where only $28 \%$ of young children born to adolescent mothers were in the normal range for cognitive development.

Findings have shown that African American and Puerto Rican adolescent mothers are at a higher risk for depression (Leadbeater, Bishop, \& Raver, 1996) and for maltreating their children (Bolton, 1990) than are adult African American and Puerto Rican mothers. Children who are maltreated and have a mother who is very depressed are more likely to have internalizing and externalizing problems than those children who are exposed to only one or neither of these risks (Black et al., 2002). The lives of adolescent mothers are often embedded in a network of risk factors for their children (Wakschlag, Gordon, Lahey, Lobe, Green, Leventhal, 1999) and any combination of risk factors will have greater effects on a child than will one risk factor alone (Black et al.).

As is evident in the preceding paragraphs, the development of children of adolescent mothers is often negatively influenced by the circumstances in which they live. Some evidence was given to show that the type of caregiving children receive, a topic that will be discussed more below, also impacts development. Next we will discuss research on the common characteristics of adolescent mothers in order to give the reader a sense of why adolescent mothers' caregiving competence may be perceived more negatively than that of adult mothers. 


\section{Characteristics of Adolescent Mothers}

Research has shown that there are many differences between adolescent and adult mothers' caregiving styles. Adolescent mothers, as a group, are less responsive and verbally stimulating to their infants (Levine, Garcia Coll, \& Oh, 1985), and are more punitive and use harsher discipline methods with their children than adult mothers (Smith \& Brooks-Gunn, 1997). When utilizing a poor parenting style, adolescent parents may put their children at risk for socioemotional and cognitive delays, making them more likely to have internalizing and externalizing problems, and may put them at a higher risk for injury due to harsh discipline styles.

Adolescent mothers often are of low socioeconomic status, are less likely to finish high school and attend any post-secondary schooling, are less likely to be married, and are less likely to receive adequate social support than are adult mothers (Culp et al., 1988; Wakschlag et al., 1999). An adolescent mother who is unmarried may have an even harder time finishing high school if she is left to work and care for her child on her own, which further contributes to the stress of living in low socioeconomic status conditions. Children living in a situation such as this are at a disadvantage compared to children who live in a less stressful home environment.

Research shows that adolescent mothers are less likely to have realistic developmental expectations for their children (Tamis-Lemonda et al., 2002; Vukelich \& Kliman, 1985), are less happy about their pregnancy, and are likely to view their infants less positively than older mothers (Culp et al., 1988), all of which can affect the young mothers' competence at caring for their children. The way a mother feels about her role as a parent and how she perceives her infant can have a large effect on her parenting competence. Each of these findings will be discussed in greater depth below.

McAnarney and colleagues (1986) looked at interactions in African American, Caucasian, and Hispanic adolescent mother-infant dyads and in adult mother-infant dyads. The researchers found that adolescent mothers were more impatient with their 1-year-old children, were less likely to initiate vocalizations and reinforce their children's vocalizations, were less cooperative with the researchers, and were less accessible to their children than were adult mothers. McAnarney and colleagues also found that around 9 to 12 months of age, when infants become more exploratory and able to move around, adolescent mothers were more likely to limit their infants' freedom and mobility than were adult mothers. A child who has limited freedom for exploration may be mentally and physically understimulated as compared to children who are 
able to freely explore their environments, which could result in cognitive and physical development delays (McAnarney et al.).

As infants become better able to move around on their own between 9 and 12 months of age, they also become less dependent on their mothers. Barratt and Roach (1995) found that as their children approach 12 months of age and become more independent, Caucasian adolescent mothers are less likely to respond vocally to their infants' vocalizations. These mothers may be putting their children at risk for language delays as most 12-month-olds are in the one-word stage of development and need the verbal stimulation of those people surrounding them to reach the stages of language development that follow the one-word stage (Barratt \& Roach).

Levine and colleagues (1985) also compared interactions between Caucasian adolescent mothers and their infants with interactions between Caucasian adult mothers and their infants. The results of this study indicated that adult mothers showed more positive affect toward their infants, better demonstrated tasks to their infants when asked to, were more likely to encourage their infants to try a task involving toys, and talked more to their infants than did the adolescent mothers. These findings demonstrate that infants of adolescent mothers may not have the same benefits as those infants of adult mothers who are encouraged to do tasks alone because that lack of encouragement could hinder the infants' cognitive development (Levine et al.). Cognitive developmental delay could lead to difficulties for the child when he or she reaches school age as he or she may be less intellectually prepared for formal schooling as compared to other children of the same age, which could further lead to problems with the child's self-esteem and academic abilities.

Levine and colleagues (1985) used evidence from Field, Widmayer, Stringer, and Ignatoff (1980) to indicate a possible reason for the previously mentioned findings that adolescent mothers talk less to their infants and do not encourage them as much as do adult mothers. Field and her colleagues found that African American adolescent mothers had less realistic notions about infant development than did adult mothers, in that the adolescent mothers believed that infants acquired milestone skills earlier than usual. The adolescent mothers in the Levine and colleagues' study may also have misestimated the time at which milestones in development should occur. For instance, an adolescent mother may believe that, on average, healthy infants begin to walk at 9 months of age instead of at 12 months, which is closer to the age that the average infant walks without help. Thus, they may believe their own infants are 
Perceptions of Mothers and Infants 9

developmentally slower than other infants if their infants are not exhibiting certain behaviors as early as the mothers expect them (Karraker \& Evans, 1995). This belief stems from adolescent mothers' overly high expectations for their own infants' behavioral development. Consequently, these mothers could come to expect less from their infants than the infants are capable of as they may think their infants are cognitively and physically delayed (Karraker \& Evans). If mothers have fewer expectations for their children, they may encourage their children less because they may feel that the children cannot carry out certain tasks. As previously discussed, children who receive little encouragement may be at a cognitive disadvantage compared to those who are regularly encouraged.

Other studies have also shown that adolescent mothers tend to misestimate the average time at which many developmental milestones occur. Tamis-Lemonda and colleagues (2002) found that adolescent mothers from diverse backgrounds (African American, Caribbean, West Indian, Puerto Rican, Dominican, and South American) understood the sequence of milestones in the first year of life, but they had a harder time determining the average ages at which milestones appeared. Similar to previous research, Tamis-Lemonda and colleagues found that adolescent mothers tended to believe that milestones occur in average, healthy babies earlier than they usually take place. Adolescent mothers who misestimate the age at which events occur may become frustrated with their own children. This frustration could cause the mothers to become physically punitive toward their children, which could escalate into physical abuse (TamisLemonda et al.).

\section{Successful Adolescent Mothers}

As is evident in the previous section, adolescent mothers, as a group, have many characteristics that may lead people to perceive them as incompetent mothers. Yet there are many adolescent mothers who are successful in their parenting endeavors as well as many children born to adolescent mothers who find success in academics and interpersonal relationships. Many studies have tried to pinpoint certain characteristics that may lead to competent parenting by adolescent mothers (Herrmann, Van Cleve, \& Levinsen, 2001; Luster, Bates, Fitzgerald, Vanderbilt, \& Key, 2000; Sommer et al., 2000). Having only one child, living in a safe neighborhood, and graduating from high school are all maternal characteristics that are associated with successful mothering (Luster et al.). There is evidence that adolescent mothers who are emotionally prepared for mothering, who are able to successfully and quickly adjust to 
having a new infant, who have average or above average IQ, and who have strong social support are more likely to competently raise their children than adolescent mothers without these advantages (Sommer et al.).

Positive social support seems to be a key predictor of adolescent mothers' adjustment to parenting, their parenting skills, and child outcomes (Bunting \& McAuley, 2004; Herrmann et al., 2001; Luster et al., 2000; Riggs, Holmbeck, Paikoff, \& Bryant, 2004; Sommer et al., 2000). Social support, especially from family members, such as the child's grandmother and father or other father figure, may moderate the effects of other maternal characteristics, such as depression and poverty, which may otherwise negatively influence the mother's caregiving and the child's development (Sommer et al.). Adolescent mothers who feel less supported are more likely to be depressed, which is also associated with poorer outcomes in children (Bennett Murphy, Gilliland, \& Griswold-Rhymer, 2001). Also, adolescent mothers who feel as though they had little support in their parenting when they had their child also tend to monitor their child less (Riggs et al.).

Luster and colleagues (2000) found that the most cognitively competent children of African American and Caucasian adolescent mothers in their study had mothers who went further in schooling and who were more likely to be employed at the time of the child's assessment (54 months of age) than the adolescent mothers of less competent children. The more competent children were also more likely to be living with the mother and a father or father figure. Those mothers who lived with the child's father or another male were more likely to complete more years of schooling than those mothers who did not live with a male companion. Also, in a meta-analysis of adolescent parenting research in the U.S. and the U.K., the presence of a male partner in the home was associated with better psychological and financial outcomes for the adolescent mothers and positive parenting outcomes for their children (Bunting \& McAuley, 2004). This evidence supports the findings that social support is important in the lives of adolescent mothers and their children. To the extent that people are aware of or believe in the benefits of a father figure for children of adolescent mothers, they may perceive adolescent mothers and their children more positively when a male partner is also living with the child. Therefore, the presence of a male partner will be manipulated in the present study. Participants may believe that the presence of a partner will allow the mother to finish school and hold down a 
job because she will have his added help with childcare. Participants may also see the presence of a father figure as being important to the infant's psychological development.

In the Luster and colleagues' (2000) study, those children who lived with their mother and a father figure were more likely to live in safe neighborhoods than those children living with their mothers alone. In this case, the presence of a male may have made it more likely that the mother would be working, as he may have taken on some of the parenting tasks and allowed the mother to have more time for her working endeavors. The male partners may also have contributed to the family's income, which may have made it more likely that the mother could afford to put her child into day care, also allowing her to have a job. With the mother's and the partner's joint incomes, the child is more likely to live in a better neighborhood than children who live alone with their mothers (Luster et al.). Living in a better neighborhood makes it more likely that the child will have access to better schools than those living in low-income areas. Having a joint income also makes it more likely that the child will have the amenities that are necessary for healthy development, such as health care and nutritious foods.

Greater social support may lead to higher self-esteem for adolescent mothers (Herrmann et al., 2001). An adolescent mother's self-esteem has been shown to have an effect on her child's development in many domains (Herrmann et al). Hurlburt and McDonald (1997) found that the level of adolescent mothers' self-esteem was associated with parenting skills. Children whose mothers had higher self-esteem tended to be more socially competent at $4 \frac{1}{2}$ years of age (HubbsTait et al., 1994). Mothers who have greater social support and higher self-esteem may also be more gregarious, which could allow for more opportunities for their children to interact with other children and develop social skills. Those mothers who have lower self-esteem and less social support may not interact with others as much and consequently may not provide as many opportunities for their children to interact with other children. Day care is another way that children can interact with other children and develop social skills. Low-income adolescent mothers may not be able to afford day care for their children, however, not allowing their children to reap the benefits of such socialization.

As is evident in the preceding paragraphs, there can be many factors in an adolescent mother's life that can make her a successful and competent caregiver. We know that not all adolescent mothers are incompetent caregivers, yet there are many common characteristics of 
adolescent mothers that may make them, as a group, a target for stigmatization. Next we will discuss stigmatization and the effects it may have on adolescent mothers.

\section{Stigmatization of Adolescent Mothers}

A stigma is any undesirable or objectionable characteristic as it is deemed by a perceiver. Erving Goffman (1963) uses the word "discrediting" (p. 3) when defining stigmas, by which he meant that a stigma is a trait that is seen as disgraceful and dishonorable. Stigmas may be natural in origin (e.g., birth defect, debilitating disease) or brought on by one's self (i.e., a convict, drug abuser). Those who are stigmatized are seen as having a characteristic that deviates from the norms of society. Stigmatization is linked to societal values, as stigmas are dependent on the society in which a person lives. Cultures around the world have diverse values and thus different cultures stigmatize people for different reasons. Middle class values in the United States deem adolescent motherhood a negative occurrence that should be avoided (Rutman et al., 2002).

Adolescent mothers may be stigmatized simply because they are visibly young and have a child. This stigma would be categorized by Goffman (1963) as a "blemish of individual character" (p. 4). These mothers have what Goffman would call a visible stigma as one can simply observe them and their infants and assume they are young mothers. The observer may then make many assumptions about the mothers and their infants from this observation. These assumptions, although perhaps unsupported and unconfirmed, can affect the way those who believe these assumptions to be true act toward adolescent mothers.

Stigma research has looked at the origins and consequences of stigmatization in many different facets of human life (Link \& Phelan, 2001). Some popular topics in stigma research are race, mental and physical disabilities, income status, and obesity. When looking at the various conceptualizations of stigma one major theme is evident in every definition: those who are stigmatized have a characteristic that somehow deviates from the norms of society (Goffman, 1963). When relating society's norms with this definition of stigma it is easy to recognize that adolescent parenthood can fall into this classification of deviating from American society's accepted norms.

The nature of stigmatization involves assumptions about a target's lifestyle. Those who believe their suppositions about a target's life to be true, without knowing anything more about the target than his or her stigma, are likely to make erroneous judgments about the target. Making these judgments can also be called stereotyping. A stereotype is an idea about the 
attributes that a person may possess, based on a perceivable characteristic, whereas a stigma is a person's actual characteristic. Stereotyping acts as a cognitive shortcut, allowing people to make assumptions about another individual without having to spend the time to get to know him or her. Most times, stereotyping can be automatic, not allowing the perceiver to realize that he or she is making biased assumptions about another (Fiske, 1998).

Stigmatization can have many dramatic effects on its targets. Stress can result from being the target of stigmatization (Miller \& Kaiser, 2001). Much of the time this stress is added to the already occurring stress, which is a product of existing circumstances that had originally made a person a target for stigmatization. For example, in the case of adolescent mothers, these mothers first have to cope with all the stressors that come with being a young mother, and at the same time, they have to manage the stress that arises from peoples' negative behaviors toward them because they are adolescent mothers.

Self-esteem may play a role in how stigmatization affects a target. Those who base their self-esteem on appraisals by others are more likely to feel dejected by another's negative judgments. Those who do not base their self-esteem on the external assessments of others and instead rely on their own assessments of themselves will not be as strongly impacted by stigmatization (Crocker \& Quinn, 2000). Adolescent girls often base their appraisals of themselves on the assessments of others (Marton, Connolly, Kutcher, \& Korenblum, 1993). Therefore, an adolescent mother may be especially likely to be negatively affected by stigmatization, as she is more apt to base her self-esteem on the appraisals of others than do adult mothers.

Depression often co-occurs with low self-esteem. Adolescent mothers are somewhat more likely to be depressed than are adult mothers (Leadbeater et al., 1996). This increased susceptibility to depression and low self-esteem may make adolescent mothers more likely to succumb to others' expectations and therefore believe themselves to be unfit mothers, or become less self-efficacious with their parenting abilities. Self-efficacy involves perceptions of one's own abilities to capably perform in a certain situation. Mothers who feel more self-efficacious about their caregiving abilities are more successful caregivers (Teti \& Gelfand, 1991). Thus, if an adolescent mother begins to believe in others' negative perceptions of her, she may feel less self-efficacious about her caregiving abilities and consequently become a less competent 
caregiver. The mother has therefore confirmed the perceivers' negative expectations of her, a phenomenon that will be discussed in depth in the following section.

\section{Expectancy Confirmation}

The process of expectancy confirmation occurs when the expectations a person has for another person influences their interaction. The perceiver, or the one who has previously developed a set of notions about a target, or the person with the stigma, may have such pervasive expectations that the expectations change the way this perceiver acts when in contact with the target (Darley \& Fazio, 1980). The perceiver may have developed expectations about a certain group of individuals from some sort of contact with or observations of one or more people in this group (Darley \& Fazio). These expectations are often grossly overgeneralized as the perceiver may begin to view the expectations as being true for everyone in the same group. The expectations that are developed can be positive or negative.

There are many cases where a target may be acting differently than he or she normally would because of some circumstance, and yet a perceiver may develop expectations for the whole group that this person belongs to from this conditional evidence (Darley \& Fazio, 1980). For example, if the perceiver has had no contact with adolescent mothers and observes an adolescent mother ignoring her infant's cries, this perceiver may then believe that all adolescent mothers act like this, when in actuality the mother may be ignoring the cries of a colicky baby who cannot be soothed.

As previously mentioned, expectations can be positive or negative, but for the sake of this topic we will discuss those expectations that are negative. If a perceiver has negative expectations for the behaviors and characteristics of a target, the perceiver may act more negatively toward the target. The perceiver may pay more attention to those behaviors that are in line with his or her expectations of the target, while at the same time regarding any behavior that may negate the expectations as being temporary or contingent traits that are not usually seen in the target's character (Darley \& Fazio, 1980). The target may then interpret the meaning of the perceiver's actions and respond to the actions in a way that confirms the perceiver's beliefs, thus creating what is called a self-fulfilling prophecy. Beyond this last step in the perceiver's and target's interactions, the target may look for meaning behind his or her own behavior that occurred during the interaction (Darley \& Fazio). The target may, over many such interactions with similar perceivers, begin to infer something new about himself or herself (Darley \& Fazio). 
This inference may be that he or she does have the characteristics that the perceivers expected from him or her, which can lead to a breakdown in self-esteem and self-efficacy (Crocker, Major, \& Steele, 1998).

One can understand how the process of expectancy confirmation might occur between adolescent mothers and perceivers with negative expectations of adolescent mothers (see Figure 1). If a perceiver who has negative notions about adolescent mothers acts in a negative manner to an adolescent mother with whom he or she comes into contact, this adolescent mother may interpret the perceiver's behavior as being negative to her. The mother may then act in a negative way toward the perceiver, which will confirm the perceiver's negative expectations for the mother. For instance, if a perceiver is rude to an adolescent mother who is not soothing her crying child, the adolescent mother will likely be taken aback by this rude behavior and perhaps get frustrated by the behavior, which may come across to the perceiver as frustration at the child's crying. After the interaction has ended, the perceiver may leave the situation with confirmation of his or her expectations while the adolescent mother may begin to deduce something negative about herself. After many such interactions, the mother may begin to believe that she is an ineffectual mother. As was mentioned in the previous section, the mother may feel less self-efficacious about her parenting abilities and thus become a less competent caregiver (Teti \& Gelfand, 1991).

Those who have negative perceptions about adolescent mothers may not consciously know of these perceptions or may not be willing to admit to having these negative perceptions when asked. In order to control for such circumstance one can use different tactics to find the true nature of a person's beliefs. One tactic of interest in this type of research is what is called a labeling study, which is where the labels that are given for the stimuli under study are thought to influence the way participants interact with or rate these stimuli independent from the actual characteristics or behaviors of the stimuli.

\section{Labeling Studies}

Many studies in the past have used experimental labeling procedures to identify peoples' stereotypes about different targets ranging from individuals with mental retardation (Fernald, Williams, \& Droescher, 1985) to infants who were born prematurely (Epps, 1993; Stern \& Hildebrandt, 1984; 1986; Stern, Karraker, Sopko, \& Norman, 2000; Stern \& Karraker, 1988; $1989 ; 1992)$. The labeling procedure often entails labeling the same stimulus with two or more 
different labels. The participants are provided with one or the other label for the same stimulus and then asked to rate the stimulus on a number of scales. Participants often rate the stimulus differently based on the label it was given.

For example, one study found that mothers of full-term and premature infants rated the premature-labeled infants as being smaller, having poorer cognitive development, and being less outgoing than those infants who were labeled as being born at full-term (Stern \& Karraker, 1992). Some of the other studies in this area have also found that premature-labeled infants were thought to be weaker, slower (Stern \& Karraker, 1988), more immature, less cute (Stern \& Hildebrandt, 1986), more passive, and less intelligent (Stern \& Hildebrandt, 1984) than fullterm-labeled infants.

Other labeling studies have looked at the different perceptions people have of infants as well as different interactions with infants based on their gender labels (Lewis, Scully, \& Conder, 1992; Vogel, Lake, Evans, \& Karraker, 1991). For example, Lewis and colleagues found that, in interactions with infants wearing sex-neutral clothing, adult participants used more masculine toys when playing with male-labeled toddlers than when playing with female-labeled toddlers. The evidence above shows that there are effects due to the labeling of stimuli.

\section{Statement of the Problem}

Little is known about the way adolescent mothers and their infants are perceived by others. No research to date in the social sciences has discussed the possibility that adolescent mothers may be negatively influenced by others' negative expectations of them and that such expectations may actually endanger these mothers' abilities to competently and efficaciously raise their children. The scope of the current study, however, did not allow for such an in-depth analysis of this suggestion and instead focused only on the existence of negative perceptions. More specifically, this study examined whether or not participants had negative perceptions of adolescent mothers and their infants.

Participants were asked to rate mothers and infants on a variety of scales after viewing a videotape of mother-infant interaction. The participants were told that the mothers in the videos were either adolescents (17-year-olds) or adults (25-year-olds), constituting the Age Label, and either single and living alone or married and living with their husbands, constituting the Marital Status Label. Thus, before viewing each video, participants were told they were about to watch an adolescent-unmarried mother and her child, an adolescent-married mother and her child, an 
adult-unmarried mother and her child, or an adult-married mother and her child interacting with one another.

Hypotheses

Hypothesis 1. Participants will rate adolescent-labeled mothers more negatively than adult-labeled mothers.

Hypothesis 2. Infants of adolescent-labeled mothers will be rated more negatively than infants of adult-labeled mothers.

Hypothesis 3. The interactions of adolescent-labeled mother-infant dyads will be rated more negatively than the interactions of adult-labeled mother-infant dyads.

The rationale behind Hypotheses 1, 2, and 3 is that adolescent mothers and their children, as a group, have more negative characteristics than adult mother and their children, making it more likely that participants will hold stereotypes about adolescent mothers and their infants. Thus, those participants who have negative stereotypes of adolescent mothers and their infants as a whole will perceive the adolescent mother-infant dyads in this study negatively.

Hypothesis 4. Participants will rate unmarried-labeled mothers more negatively than married-labeled mothers.

Hypothesis 5. Participants will rate infants of unmarried-labeled mothers more negatively than infants of married-labeled infants.

Hypothesis 6. Participants will rate the interactions of the unmarried-labeled motherinfant dyads more negatively than the interactions of the married-labeled mother-infant dyads.

The rationale behind Hypotheses 4, 5, and 6 is that mother-infant dyads that are labeled as living with a spouse will be perceived as having more social support than the mother-infant dyads that are labeled as living alone. Participants will probably believe that there is a difference between those mothers who have a child out of wedlock and those mothers who are married when they have a child in how that child will be raised. The challenges that come with having a child are well-known and participants will most likely believe that it is better for a child to be raised by both parents instead of just one.

Hypothesis 7. Mothers labeled adolescent and unmarried and their infants will be rated more negatively than mothers labeled adolescent and married, adult and unmarried, and adult and married, as well as their infants. The rationale behind Hypothesis 7 is that the two risk factors of adolescent motherhood and living alone combined will be seen as a more negative 
circumstance than the presence of either of these risk factors alone, or in the case of the mothers labeled adult and living with a spouse, neither risk factor.

Method

\section{Participants}

Participants were 153 college student volunteers from undergraduate psychology courses who were compensated for their time with extra credit in their psychology classes. Five participants were dropped from the final analyses for being too old to meet the age criterion of 18 to 20 years of age, 17 were dropped for having incomplete data, and 8 were dropped for failing the manipulation checks. Participants' data were reviewed regularly and participants with problematic data were replaced by other participants of the same gender and same condition. Included in the final analysis were 128 participants (64 male and 64 female), ages 18 to 20 (mean age $=19.06, \mathrm{SD}=.79)$. All of the participants were enrolled in college classes at the local university and most were in their first or second year of college (48.4\% freshman, 37.5\% sophomores, and $14.1 \%$ juniors and seniors). Because the students were selected from introductory-level classes, there was a wide range of participant majors. The largest proportion of participants were in Psychology (18\%), followed by Business (11.7\%), Exercise Physiology $(8.6 \%)$, and Nursing (7.8\%); the remainder of the college majors each made up less than $5 \%$ of the sample. The vast majority of the sample was Caucasian $(88.3 \%, \mathrm{n}=113)$. The remainder were African Americans ( $(n=4)$, Hispanic $(n=4)$, Asian Americans $(n=2)$, or “other" $(n=5)$. In this sample, only two participants were married, whereas 93\% were unmarried and not living with a significant other $(\mathrm{n}=119)$ and $5.5 \%$ were unmarried and living with a significant other $(n=7)$. None of the participants had children.

Approximately $71 \%$ of the participants reported having had contact with at least one adolescent mother in the past 5 years. Participants were asked to report their relationship to as many as five adolescent mothers. Only one participant knew as many as five adolescent mothers. In total, the 128 participants collectively knew 151 adolescent mothers. Four (3\%) of the participants reported having a sibling who was an adolescent mother. Another 17 (13\%) of the participants had a member of their extended family (i.e., cousins) who was an adolescent mother. The vast majority of the known adolescent mothers were friends of the participants (110 mothers, or $73 \%$ of known mothers). Only 20 of the mothers were casual acquaintances of the participants. 
Stimuli

Four stimulus videotapes were produced prior to the start of the study; these tapes included mothers interacting with their infants. The mothers in the stimulus tapes were Caucasian, 25-30 years of age, and were contacted by sending letters to names listed in county birth records. Only those mothers who had a 6-7-month-old infant at the time of the videotaping were contacted to participate in the stimulus production. Because the age of the mother is not included in the county birth records, mothers were asked about their age in a follow-up phone call after the letters were sent; the mothers were invited to participate in the study if they met the age requirement. Approximately 50 mothers were sent letters and those living within the city limits were then called (roughly 30 mothers) to ask if they wanted to participate. Ten mothers agreed to come into the infant development laboratory so that the stimulus videotapes could be produced. The final four videotapes used in the study were selected through a pilot study that determined which mothers could pass as both adolescents and young adults. Four graduate students and one undergraduate student watched all of the videotapes and were asked to state which of the mothers looked the youngest. The results were unanimous - all five of the pilot study participants chose the same four mothers as looking the youngest. The mothers in the stimulus videotapes were asked not to wear too much jewelry or make-up to the laboratory. Two of the mothers in the stimulus video were wearing plain white shirts, one was wearing a sweater, and the last was wearing a light-colored button down shirt (viewers could only see from the waist up). Their shirts and hair styles were all what could be deemed appropriate for either a teenager or someone in their 20's. These controls helped make the income status of the mothers indistinguishable. The mothers were married and were asked to remove their wedding and engagement rings during the taping of the videos so as not to give away their actual marital status. Also, during the taping of the stimulus videos, mothers were given the same simple toys with which to interact with their infants and were told to act as they naturally would in face-toface contact with their infants.

Each stimulus video shown to the participants was approximately 2 minutes in length and did not contain any footage of the infants crying. These 2-minute segments were selected from a longer recording of mother-infant interaction. The segments were chosen on the basis that mothers and infants were playing with one another during the whole segment and the infants were not upset or crying. 


\section{Procedure}

Participants watched each of the four prerecorded stimulus videotapes of women interacting with infants. Before showing these videos a video montage of infants around the age of 6 months was shown to the participants in order to familiarize them with how 6-month-old infants look and behave. This montage video was created by editing together videotapes of four male infants around the age of 6 months. In this video, the infants were seated in a high chair by themselves and given a toy with which to play.

Before viewing the first videotape, participants read a set of instructions, which they utilized throughout the study (see Appendix A). A cover story was told to the participants so they would not suspect the intended reason for the study; participants were told that the purpose of the study was to see how the characteristics of four mother-infant dyads that have had similar experiences compare to one another. The participants watched the videos in mixed-gender groups of four to eight participants, whenever possible. The groups of participants who were scheduled for the same session were randomly assigned to video presentation groups. Prior to showing each videotape, the participants read a brief, fictional description of the mother-infant dyad's life from a packet distributed at the start of the study (see Appendix B). Participants were told that the mother was either a 17-year-old or a 25 -year-old. The participants were also told that the mother and her infant were either living with her husband or that they lived alone. Thus, each of the videos was preceded by one of four vignettes: adolescent-unmarried, adolescentmarried, adult-unmarried, or adult-married.

The presentation of the videos was counterbalanced so that each video was shown first to an equal number of participants within each label condition (see Table 1). The videos were labeled 1, 2, 3, or 4. During the video presentations, 1 always followed 4, except when 1 was the first video shown. The vignettes were ordered so that each of the four vignettes was read first, depending on the condition. The vignettes were each read first an equal number of times. Also, throughout each of the four cells that utilized the same presentation order, no vignettes were read twice for the same video. The four vignette orders were the same for each of the four presentation orders. A total of 16 conditions were tested, with 8 participants ( 4 males, 4 females) in each condition. Only the ratings of the first video presented to each participant were analyzed, allowing for between-subjects analyses. 


\section{Measures}

The measures used for this study are discussed next. Except for the Mother Rating Scales and the background questionnaire, all measures were adapted from past research studies. The measures have all been changed, and thus the previously reported psychometric properties of the scales are not applicable to this study. The reliabilities for each scale based on the current data are provided in the individual descriptions of the scales; all reliability coefficients were calculated using coefficient alpha. All of the measures included ratings that were based on a 7point scale, where 1 represented the least positive and 7 represented the most positive score.

Infant Ratings. After viewing each video, participants were asked to rate the infant on the Infant Rating Scale (IRS), which was adapted from Stern \& Karraker (1988). The IRS examined participants' overall perception of the infant's physical appearance, cognitive fitness, sociability, behavior, and physical potency, and also assessed how much the participants liked the infants. The participants were also asked to speculate on the infant's future outcomes on items assessing future marital status, career achievement, and psychological health. The overall reliability on the IRS was .88.

Items in the IRS were placed into two groups based on conceptual relatedness and reliability analyses, and then mean scores for each group were calculated. Items were recoded when necessary so that higher scores indicated more positive ratings. The Overall mean score included the following items: quiet/loud, pleasant/cranky, well-behaved/not well behaved, cuddly/not cuddly, smart/dumb, curious/not curious, competent/incompetent, mature/immature, big/little, fine-featured/large-featured, cute or attractive/not cute, strong/weak, passive/assertive, coordinated/uncoordinated, shy/friendly, happy/sad, fun to play with/not fun to play with, overall liking, and typical/untypical behavior $(\alpha=.84)$. Although previous researchers utilizing this measure formed several clusters within this scale (e.g., Stern \& Karraker, 1998), reliability analyses did not yield strong alphas for two of the clusters utilized by Stern and Karraker, and thus all 19 items were included in the Overall mean score because their overall reliability was strong. The second mean score included all of the Future items (future successful/unsuccessful, future well-adjusted/maladjusted, future unhappy/happy, future single/dating or married, and future poor/financially stable). The resulting Chronbach's alpha was .81 for these items.

Mother Ratings. The participants were then asked to rate the mother on the Mother Rating Scale (MRS), which examined her responsiveness to her infant, her physical appearance, 
her cognitive fitness, her behavior, and the participants' overall liking of her (see Appendix D). The participants were also asked to speculate on the mother's future outcomes on items assessing future marital status, career achievement, and psychological health. The overall reliability on the MRS was .94.

Items in the MRS were grouped based on their conceptual relatedness and reliability analysis; mean scores were calculated for each group. The items included in the groups and their Chronbach's alphas were as follows: Responsiveness (kind/unkind, careful/careless, gentle/rough, nurturing/neglectful, responsive/unresponsive, and patient/ impatient; $\alpha=.81$ ), Sociability (fun/boring, happy/unhappy, talkative/quiet, friendly/shy, relaxed/anxious; $\alpha=.86$ ), Physical Appearance (well-rested/tired, well-groomed/unkempt, and healthy/unhealthy; $\alpha=.72$ ), Intelligence (competent/incompetent, intelligent/unintelligent, and mature/immature; $\alpha=.75$ ), and Future (future happy/unhappy, future successful/unsuccessful, future healthy/unhealthy, future married/single or divorced, and future good mother/ bad mother; $\alpha=.89$ ).

Interaction Rating Scales. Participants were also asked to rate the interaction of each dyad using a revised version of Field's Interaction Rating Scale (Field, 1980; see Appendix E). This scale was revised to make it more easily understood by untrained coders such as college students and to create a 7-point scale instead of a 3-point scale, allowing for more sensitivity. Infants' interaction behaviors were rated on the Infant Interaction Rating Scale (IIRS), which assessed infants' active interaction, mood, physical activity, and vocalizations. The overall reliability on the IIRS was .79.

All the items except one (overall Liking) in the IIRS were also combined into one mean score for the reason that the alpha for the combined score was strong. The items in the IIRS Overall mean score were as follows: attentive/not attentive, very interactive/ not interacting, interest/little interest, frequent smiling/ frequent cry face, no fussing/frequent fussing, alert/sleepy, relaxed/squirming, and frequent vocalizations/ no vocalizations; $\alpha=.79$ ). Liking was utilized as one single rating score.

Mothers' interaction behaviors were rated on the Mother Interaction Rating Scale (MIRS), which assessed mothers' active interaction, mood, and vocalizations. The reliability of the MIRS was .93.

As with the IIRS, all the items except overall Liking were combined into one mean score because all the items included in the Overall means score yielded a strong alpha. The items 
Perceptions of Mothers and Infants

included in the Overall mean score were as follows: responsive/ not responsive, attentive/not attentive, very interested/little interest, very interactive/not interacting, frequent engagement/no engagement, very alert/very drowsy, very affectionate/no affection, frequent smiling/ frequent sad or angry faces, and frequent vocalizations/no vocalizations $(\alpha=.92)$. Liking was used as a single rating score.

Finally, after all four videotapes were shown, participants were asked to complete a personal background survey (see Appendix F), which inquired about participant age, major in college, religion, marital status, liking of and amount of interaction with infants, amount of interaction with adolescent mothers. Participants were also asked to give an overall rating of the competence of adolescent mothers to successfully raise their children.

\section{Analyses}

Preliminary analyses assessed the effectiveness of the manipulations of the Age Label and the Marital Status Label by analyzing the effects of these labels on participants' answers to the manipulation check items. Manipulation checks were employed in the IRS and MRS; participants were asked questions about information that was contained in each vignette (e.g., "What was the age of the mother you just saw?" or "Was the mother you just saw (circle one)?; A. Living alone with the infant or B. Living with the infant and a husband.") to be sure they remembered the labels for each dyad. The data of those participants who failed the manipulation check was replaced by data from other participants.

Multivariate analyses of variance were conducted to analyze the effects of Age Label, Marital Status Label, participant Gender, and Video Number on the participants' perceptions of the mothers, infants, and mother-infant interactions. MANOVA's were conducted before ANOVA's because the dependent variables in each measure were moderately correlated (IRS mean scores: .56; MRS average mean score correlations: .58, range: .49-.69; IIRS mean scores: .61; MIRS mean scores: .45) and thought to be conceptually related. If ANOVA's were conducted and found to be significant, it would be difficult to say that significance was found for completely separate dependent variables, because the dependent variables are conceptually and statistically related. Also, MANOVA creates a linear composite of the dependent variables, which maximizes the differences between the groups defined by the independent variables, thus allowing for ease of finding group differences. If the dependent variables were instead highly correlated or had zero correlations, the use of ANOVA would have been warranted. When the 
Perceptions of Mothers and Infants

dependent variables are correlated with one another the findings from separate ANOVAs is redundant. Another reason that the use of MANOVA is warranted is that the family-wise error rate becomes higher with the use of ANOVA and the odds of finding significance because of chance rises with the repeated use of the same sample; thus, MANOVA reduces the chance of making Type I errors. All assumptions of MANOVA were met. The sample sizes were equal and there was no missing data, variances across the dependent variables were equal (according to Box's M tests), the dependent variables were distributed in a linear fashion, and the observations were all independent. Multivariate outliers were assessed through output in SPSS. The outputted outliers were deleted and analyses were rerun. The outliers were found not to influence the results; thus they were not changed or deleted. The dependent variables were also slightly skewed to the higher ratings (range of skewness for mean scores: -.13 to -.43, standard error $=.22$; range of kurtosis for mean scores: .00 to .88 , standard error $=.43$ ), but when the dependent variables were skewed, it was always in the same direction. According to Tabachnik and Fidell (2001), there is no need to reject the assumption of normality when the distributions are only slightly skewed and all skewed in the same direction. Also, when non-normality is caused by skewness and not because of outliers, the F-test is still very robust (French \& Poulsen, 2002).

Between-subjects comparisons were conducted using the first stimulus video viewed by each participant. In cases where a multivariate main effect or interaction was significant, univariate results are detailed. Specific tests of each hypothesis are described below:

Hypothesis 1: Participants will rate adolescent-labeled mothers more negatively than adult-labeled mothers. This hypothesis would be supported by a significant main effect of Age Label on ratings of the mothers.

Hypothesis 2: Infants of adolescent-labeled mothers will be rated more negatively than infants of adult-labeled mothers. This hypothesis would be supported by a significant main effect of the Age Label on ratings of the infants.

Hypothesis 3: The interactions of adolescent-labeled mother-infant dyads will be rated more negatively than the interactions of adult-labeled mother-infant dyads. This hypothesis would be supported by a significant main effect of Age Label on ratings of the mother-infant interactions. 
Perceptions of Mothers and Infants

Hypothesis 4: Participants will rate unmarried-labeled mothers more negatively than married-labeled mothers. This hypothesis would supported by a significant main effect of the Marital Status Label on ratings of the mothers.

Hypothesis 5: Participants will rate infants of unmarried-labeled mothers more negatively than infants of married-labeled infants. This hypothesis would supported by a significant main effect of the Marital Status Label on ratings of the infants.

Hypothesis 6: Participants will rate the interactions of the unmarried-labeled motherinfant dyads more negatively than the interactions of the married-labeled mother-infant dyads. This hypothesis would be supported by a significant main effect of the Marital Status Label on interaction ratings.

Hypothesis 7: Mothers labeled adolescent and unmarried and their infants will be rated more negatively than mothers labeled adolescent and married, adult and unmarried, and adult and married, as well as their infants. This hypothesis would be supported by main effects of Age Label and Marital Status Label on mothers, infants, and mother-infant interaction ratings.

\section{Results}

None of the 128 participants used in final analyses failed the manipulation tests on the first mother-infant dyad they viewed. More specifically, the participants all answered that the infants were around 6 months of age and they correctly stated the age and marital status of the mothers as were indicated in the vignettes.

Results are presented for each measure separately, beginning with the IRS, followed by the MRS, the IIRS, and finally the MIRS. For each measure, the multivariate effects are described first, and when significant are followed by the univariate effects. Whenever possible, interactions are interpreted by examining the conditions under which the Age Label manipulation or the Marital Status manipulation produced significant differences in ratings. Post hoc tests were carried out on all significant univariate findings; the effects of Video Number were analyzed through Bonferroni procedures and the effects of Age Label, Marital Status Label, and Gender were analyzed through t-tests. All statistics are reported in tables that are indicated in the individual discussions of the measures.

Infant Rating Scale

The IRS was analyzed in a 2 (Age Label) X 2 (Marital Status Label) X 2 (Participant Gender) X 4 (Video Number) analysis of variance (see Table 2 for IRS F-statistics and 
Perceptions of Mothers and Infants 26 significance). There was one significant main effect, that of Video Number. Also, the Marital Status Label interacted separately with Video Number, Age Label, and Participant Gender. Finally, there was one significant 3-way interaction between Video Number, Age Label, and Participant Gender. These significant findings are described separately below.

IRS Video effect. There was a significant univariate main effect of Video Number on both the Overall and the Future mean scores. For both the Overall and the Future mean scores, the infant in Video 3 had the highest average ratings (see Table 3 for IRS means and standard deviations). For the Overall mean score, the infant in Video 2 had the lowest average ratings and for the Future mean score, the infant in Video 1 had the lowest average ratings. Bonferroni posthoc analyses indicated that there were significant differences between ratings for Videos 1 and 3, 1 and 4, 2 and 3, and 2 and 4 on the Overall mean score and a significant difference between the ratings for Video 1 and Video 3 on the Future mean score (see Table 4 for results of the post-hoc tests).

IRS Marital Status X Video effect. There was a significant interaction between Marital Status Label and Video Number on the Future mean score; participants' ratings of infants' futures in different videos were influenced by the Marital Status Label. For the Future mean score, the infant in Video 2 was rated significantly more positively when the mother was labeled as being married as compared to unmarried and the infant in Video 4 was rated more positively when the mother was labeled as unmarried rather than married.

IRS Marital Status $X$ Age effect. Although there was a significant multivariate Marital Status Label by Age Label interaction, participants' ratings of infants whose mothers were labeled married or unmarried did not significantly differ across the Age Label on either the Overall or the Future mean scores. Because there was no univariate effect on the Overall or Future mean scores, the multivariate finding cannot be interpreted.

IRS Marital Status X Gender effect. Marital Status Label significantly interacted with Participant Gender on the Future mean score of the IRS. Post-hoc tests indicated that there was no significant difference between the means for gender within each marital status or for marital status within each gender. Thus, interpretation of this interaction is not possible.

IRS Age X Gender X Video effect. Finally, the 3-way interaction between Video Number, Age Label, and Participant Gender was found to be significant for the Future mean score of the IRS, but not for the Overall mean score. Male participants rated the infant in Video 1 
significantly more positively when the mother was labeled adult as compared to adolescent. For Video 3, male participants rated the infant significantly more positively when the mother was labeled adolescent instead of adult. For Videos 2 and 4 male participants did not rate the infant differently across the two age labels. Female participants did not rate the infants in any of the four videos significantly differently based on their age label.

\section{Mother Rating Scale}

A 2 (Age Label) X 2 (Marital Status Label) X 2 (Participant Gender) X 4 (Video Number) multivariate analysis was carried out on the MRS. There was a significant multivariate main effect for Video Number and a significant multivariate interaction between Age Label and Marital Status Label (see Table 5 for MRS F-statistics and significance). Both findings are described separately below.

MRS Video effect. There were significant univariate main effects of Video Number on all of the mean scores except on the Intelligence mean score. Means indicate that for all the MRS mean scores, the mother in Video 3 was rated the most positively, and the mother in Video 1 was rated the least positively (see Table 6 for MRS means and standard deviations). Bonferroni posthoc analyses indicate a significant difference between Videos 1 and 3 and 3 and 4 on the Responsivity mean score, between 1 and 3, 2 and 3, and 3 and 4 on the Sociability mean score, between 1 and 2, 1 and 3, 2 and 4, and 3 and 4 on the Physical Appearance mean score, and between 1 and 3 and 3 and 4 on the Future mean score (see Table 4).

MRS Age X Marital Status effect. For the Age Label by Marital Status Label interaction, participants' mean ratings of adolescent-labeled and adult-labeled mothers' Intelligence and Future differed within each level of the Marital Status Label (see Table 6). When mothers were described as married, they were rated as more intelligent and as having more promising futures when they were believed to be adults rather than adolescents. Ratings of the mothers described as unmarried did not differ significantly based on their age label. The Age Label by Marital Status Label interaction was not significant for the Responsiveness, Sociability, or Physical Appearance mean scores.

\section{Infant Interaction Rating Scale}

Once again, a 2 (Age Label) X 2 (Marital Status Label) X 2 (Participant Gender) X 4 (Video Number) multivariate analysis of variance was carried out on the IIRS ratings. There was a significant main effect for Video Number (see Table 7 for IIRS F-statistics and significance). 
Perceptions of Mothers and Infants

IIRS Video effect. For both the Overall mean score and the Liking rating, the infant in Video 3 was rated the most positively and the infant in Video 2 was rated the least positively (see Table 8 for IIRS means and standard deviations). Bonferroni post-hoc analyses indicate a significant difference between Videos 1 and 3, 1 and 4, 2 and 3, and 2 and 4 for the Overall mean score and a significant difference between Videos 1 and 3, 2 and 3, and 2 and 4 for the Liking rating (see Table 4). There were also significant multivariate interactions between Video Number and mothers' Age Label and between mothers' Marital Status Label and participant Gender; however, univariate analyses of variance indicated no significant interactions between Video Number and Age or Marital Status and Gender for either the Overall mean score or the Liking rating.

\section{Mother Interaction Rating Scale}

The 2 (Age Label) X 2 (Marital Status Label) X 2 (Participant Gender) X 4 (Video Number) multivariate analysis of variance was carried out on the MIRS ratings. Analyses yielded significant multivariate main effects of Video Number Age Label and Marital Status Label (see Table 9 for MIRS F-statistics and significance). These findings are described separately below.

MIRS Video effect. Further investigation of the Video Number main effect indicates that participants rated the mothers in the videos differently on both the Overall mean score and the Liking rating (see Table 10 for MIRS means and standard deviations). Once again, on both the Overall mean score and the Liking rating, the mother in Video 3 was rated the most positively and the mother in Video 1 the least positively. Bonferroni post-hoc analyses indicated significant differences between ratings of mothers in Videos 1 and 3 and 3 and 4 on the Overall mean score and between ratings of mothers in Videos 1 and 3 on the Liking rating (see Table 4).

MIRS Age effect. The Age Label had a significant effect on participants' ratings of liking of the mothers. The mothers were liked more when they were described as being adults instead of adolescents. For the Marital Status Label main effect, participants' ratings of Liking of the mothers differed significantly based on the Marital Status Label. Mothers were liked more when they were labeled unmarried than when they were labeled married.

Individual items. Finally, exploratory univariate analyses were also carried out on the individual items that comprised the significant mean scores of the four scales. Because of the large number of univariate effects on the individual items, and because these analyses are meant to be exploratory in purpose, the effects are not listed or described here. Instead, the effects of 
the individual items will be referred to when appropriate in the discussion of significant multivariate and univariate effects in the following section. The F-statistics, means, and standard deviations for each significant effect on the individual items are located in Tables 11 through 16. All significant differences in the comparisons in these tables, as determined by t-tests, are indicated with shading, but only those findings corresponding to the significant post-hoc tests of the means in the significant mean scores will be discussed in the text.

\section{Discussion}

The results of this study produced a variety of findings, some of which are counterintuitive. For example, in one instance the infants of mothers described as adolescent were rated more positively than the infants of the mothers described as adult. The same was true for some significant results involving the marital status label; in some cases the mothers described as unmarried and their infants were rated more positively than the mothers described as married and their infants. The following discussion is intended to offer explanations for the

findings detailed in the results section of this paper. This discussion will be structured according to the hypotheses.

\section{Hypotheses 1 and 2}

Neither Hypothesis 1 (Participants will rate adolescent-labeled mothers more negatively than adult-labeled mothers) nor Hypothesis 2 (Infants of adolescent-labeled mothers will be rated more negatively than infants of adult-labeled mothers) were supported by a main effect of age label. Thus, there is no evidence that the mothers described as adolescent and their infants were consistently perceived more negatively than the mothers described as adult and their infants. There was, however, some support for Hypothesis 1 based on the effect of the interaction between the age and marital status labels on the MRS ratings. This finding will be detailed with the discussion of Hypothesis 7 below. In addition, the effect of the interaction between age label, gender, and video on IRS offers some support for Hypothesis 2; this finding will be discussed next.

Age Label X Gender X Video Number effect. Male participants rated the infants in Videos 1 and 3 differently based on the age label of their mothers. First, a description of the effects of the different videos on participants' ratings is necessary to help interpret the aforementioned 3way interaction. For all four scales and mean scores in those scales, excepting the Intelligence mean score in the MRS, the video being viewed significantly influenced ratings. The mothers in 
Videos 2 and 3 and infants in Videos 3 and 4 were consistently rated the most positively on all measures. The mothers in Videos 1 and 4 and infants in Videos 1 and 2 were consistently rated the least positively on all measures. This same pattern of findings was also seen in all the individual items that had a significant main effect of video; in almost all of the individual items, the aforementioned pattern existed. Even though the researcher attempted to create stimulus videos that were similar to each other in terms of the types of interactions between the mothers and their infants and the mood of the infants, the researcher could not control the personality characteristics of the mothers and infants. There were some apparent differences in personality characteristics between the mothers and the infants. The mothers in Videos 2 and 3 were more stimulating and could be considered more "fun" than the mothers in Videos 1 and 4. The mothers in Videos 2 and 3 seemed to be more energetic in their play; one tickled the baby and moved his arms around with her hands and the other played peek-a-boo and kept the play at a fast pace. The mothers in Videos 1 and 4 mostly just handed toys to their babies and watched how they played. The infants in Videos 3 and 4 were more excited and laughed more than the infants in Videos 1 and 2.

Male participants rated the infant in Video 1 more positively when the mother was described as an adult rather than an adolescent; but the male participants rated the infant in Video 3 more positively when the mother was described as an adolescent rather than an adult. Ratings of infants' futures revealed that male participants believe the infant in Video 1 was more likely to be dating or married in 25 years when the mother was described as adult than when the mother was described as adolescent. For Video 3, the males believed the infant was more likely to be financially stable 25 years in the future when the mother was said to be adolescent instead of adult. If those males had negative perceptions of adolescent mothers, but believed that the infant in Video 3 (who was generally rated the most positively), being raised by an adolescent mother, has very positive characteristics, they may have believed that this particular adolescent mother is doing an extraordinary job of raising her child and that the infant was developing very well for being raised by an adolescent mother, and would thus rate the infant raised by her even more positively than if that infant was being raised by an adult mother. This finding indicates that there are instances in which an infant of an adolescent mother can exceed the expectations of others. This finding also signifies that male participants rated the infants in Videos 1 and 3 
differently based on the marital status label of their mothers, thus offering some support for Hypothesis 2.

\section{Hypothesis 3}

Partial support was found for Hypothesis 3 (The interactions of adolescent-labeled mother-infant dyads will be rated more negatively than the interactions of adult-labeled motherinfant dyad); participants rated the mothers using the MIRS differently based on the mothers' labeled age, but they did not rate the infants using the IIRS differently based on their mothers' labeled age. Thus, there is only partial support for the hypothesis that the perceptions of the interactions between mothers and their infants would be negatively affected by being labeled adolescent. Mothers described as adults were liked more by the participants than the mothers who were described as adolescents. Adolescent motherhood is thought to be a large social problem in the United States (Alan Guttmacher Institute, 1998; Kaiser Family Foundation, 1996). Generally, most adolescent mothers go on welfare within 5 years after the birth of their first child (Annie E. Casey Foundation, 1998). The participants may have believed that adolescent mothers are a drain on society because they are keeping themselves and their children from overcoming the cycle of poverty, and thus rated them less positively than adult mothers.

\section{Hypotheses 4 and 5}

Hypothesis 4 (Participants will rate unmarried-labeled mothers more negatively than married-labeled mothers) and Hypothesis 5 (Participants will rate infants of unmarried-labeled mothers more negatively than infants of married-labeled infants) were not supported by a main effect of the marital status label. Participants did not rate the mothers or infants differently based on the marital status label of the mothers. Thus, there is no indication that participants consistently perceived mothers or their infants less positively on the basis of the mothers' marital status alone. There was, however, an interaction effect of the marital status label on IRS ratings for some of the videos, which supports Hypothesis 5. For example, the infant in Video 2 was thought to have a more promising future when the mother was said to be married instead of unmarried; the infant in Video 4 was thought to have a more promising future when the mother was said to be unmarried instead of married. This same pattern was also found in two of the significant individual items of the IRS; the infant in Video 2 was thought more likely to be happy and dating or married in 25 years when the mother was said to be married instead of unmarried. The infant in Video 4 was thought to be more likely to be happy and dating or married 25 years 
in the future when the mother was said to be unmarried instead of married. As was mentioned before, the infant in Video 2 was generally rated the most positively and the infant in Video 4 the least positively. Perhaps participants were expecting more from an infant being raised by both parents than what was seen in Video 4, and thus did not rate that infant as positively when he was said to be raised by a married mother. This finding indicates that positive expectations can affect how infants of married mothers are perceived. If others believe that a child raised by two parents living in the same household should develop more optimally than an infant raised by just one parent who lives alone, those expectations can be disconfirmed, causing lowered perceptions of that specific infant. Thus, not only do negative expectations affect how one is perceived, but positive (good) expectations do as well. These findings also imply that infants can be judged differently based on the marital status of their mothers.

Hypothesis 6

No support was found for Hypothesis 6 (Participants will rate the interactions of the unmarried-labeled mother-infant dyads more negatively than the interactions of the marriedlabeled mother-infant dyads); participants' ratings of the mothers using the MIRS, but not the infants using the IIRS, were significantly influenced by the marital status label, however, the effects on the MIRS were not in the expected direction. Participants liked the mothers more when they were described as unmarried instead of married.

Although the direction of the marital status effect on participants' liking of the mothers was not anticipated, there is a probable explanation for this finding. It is possible that, because the mothers in this study were labeled as being 17 and 25 years old, participants did not believe that either age is old enough to be married. The average age at first marriage for women in the United States is now 25 years of age. Those women who get married at an older age are more likely to have careers and the ability to provide for themselves (Elder, 1974). College students may be especially prone to believe that delaying marriage is advantageous because one can finish school and begin a career. College students are, in essence, usually postponing getting married and settling down in order to finish school and start their careers; the average age of marriage for women was 20 in the 1950's when very few of them were going to college. Most college students in a 4-year program do not finish school until they are at least 22 years old and may not believe they would want to be married three years after graduation. As for the 17-year-olds, participants may not believe it is a beneficial for adolescent mothers to get married when they are 
so young. The rate of divorce is much higher for those who get married under the age of twenty as compared to those who get married in their mid-twenties (Warren, 2005). Also, the participants may have believed that the adolescent and married mothers in the study got married

just because they were having a child because the vignettes state that the adolescent/married mothers and their infants "have lived with the mother's husband, father of the child, since the child was born." To the participants, this may seem to be implying that they were not married or living together before the child was born.

\section{Hypothesis 7}

There was no evidence to support Hypothesis 7 (Mothers labeled adolescent and unmarried and their infants will be rated more negatively than mothers and infants of mothers labeled adolescent and married, adult and unmarried, and adult and married). Although mothers were rated differently on the MRS Intelligence and Future means scores when they were labeled adolescent-unmarried, adolescent-married, adult-unmarried, and adult-married, they were not rated the least positively when they were described as adolescent and unmarried as compared to the other three combinations of age and marital status. Inspection of the means for the findings in the MRS indicates that the mothers who were thought to be adolescents and unmarried received the second highest ratings out of those four combinations of age and marital status, with mothers described as adults and married being rated the highest. Possible explanations for these findings are provided below.

Although the means were not in the hypothesized direction, the age and marital status labels did have an interactive effect on the MRS ratings. Mothers said to be adult and married were perceived as being more intelligent and having better futures than mothers said to be adolescent and married. Even though the participants did not seem to rate married mothers as highly as unmarried mothers, they believed that the adult and married mothers had better characteristics than the adolescent and married mothers. There are a few previously mentioned explanations for this finding. Participants may have believed that adolescent mothers should not get married because they are young and much more likely to get a divorce than the adult mothers. They may also have believed that the adolescent mothers had to get married because they were pregnant because the vignette for the adolescent/married mothers states that the mother and her infant have lived with the husband since the birth of the child; the adult/married vignette states simply that the mother and her infant live with the husband. The 
Perceptions of Mothers and Infants

adolescent/married vignette could be seen as implying that the adolescent mothers had to get married because they had a child. Finally, because most adolescent mothers in the United States are unmarried when they have a child and most adult mothers are married when they have a child, participants may have believed that the adolescent mothers were deviating from a societal norm. From these findings, there seems to be some evidence that participants held stereotypes based on the combination of age and marital status.

Implications. The findings in the current study can be utilized to guide further research on the topic of perceptions of adolescent and unmarried mothers. The results indicate that adolescent and/or unmarried mothers are sometimes perceived negatively. It is possible that in some instances, adolescent and/or unmarried mothers may be perceived more positively than adult and/or married mothers given their situations in that some adolescent and unmarried mothers may exceed the expectations of others. Adolescent and unmarried mothers are, on average, disadvantaged as compared to adult and married mothers; adult and married mothers have more resources in terms of income and social support that can serve to make their child care capabilities superior to that of more disadvantaged adolescent and unmarried mothers who have little income or social support.

Anyone interacting with adolescent mothers, such as family members, friends, and especially practitioners, social workers, governmental program employees, etc. need to be aware of the possible negative perceptions they may have of adolescent mothers and the potentially adverse effects of those perceptions. When negative judgments are communicated to adolescent mothers, the mothers may begin to feel alienated, in that they may not want to interact with someone who does not approve of their lifestyle. This alienation could create a situation in which the mothers may not get the help and support they need in order to foster better parenting and lifestyle skills. Also, others may create self-fulfilling prophecies in that their expectations of adolescent motherhood as a whole may influence the way they behave toward individual adolescent mothers. The adolescent mothers may then interpret those behaviors and respond in kind, thus confirming the negative expectations about them.

The results of the current study suggest that it may not be enough to address how others perceive and act toward adolescent mothers as a group. Mothers described as adolescent or unmarried were sometimes rated more positively than mothers described as adults or married. Also, mothers described as adult and married were rated higher than mothers described as 
adolescent and married. Being that most adult mothers are married when they have a child and most adolescent mothers are unmarried when they have a child, the aforesaid finding indicates that perhaps others believe that mothers should behave as expected; when the mothers do not do what is seen as customary or typical for their situation, they are not perceived as positively. Thus, perhaps future research could also focus on how others respond to adult/unmarried mothers differently than they do to adult/married mothers.

The findings in this study also indicate that there are instances in which adolescent or unmarried mothers and their infants are perceived to have positive characteristics. In the future, research could benefit from a focus on the positive views people have of adolescent and unmarried mothers. If researchers can learn what aspects of adolescent motherhood or out-ofwedlock motherhood are thought to be positive, perhaps that information can be utilized to foster those positive aspects in all adolescent and unmarried mothers.

Limitations. The chief limitation of this study involves the significant main effects of Video Number in all of the analyses, indicating that there were differences between ratings of the mothers and infants in the different videos. The video effects interacted with the independent variables. Thus, without using Video Number as an independent variable, it is impossible to determine whether the findings resulted from the Age Label and/or Marital Status Label manipulations or from the different mothers and infants in the videos being perceived differently. The consequence of including Video Number as an independent variable is a small reduction in power. A power analysis was carried out before the study was begun, but that analysis did not include Video Number as a variable. The inclusion of Video Number as an independent variable slightly reduced the ability of the design to find significant results. Also, because there were significant effects based on the mother-infant dyad the participants were viewing, it is not possible to generalize findings across all adolescent or adult and unmarried or married mothers and their infants because participants were not rating all the mothers or infants the same as a result of their labels. Instead, the participants' ratings were affected differently based on the interaction of the information in the vignettes and the dispositions of the mothers and infants in the videotapes. Thus, this conclusion indicates that perceivers judge others not just on their disposition, but also on the basis of their situation.

Another possible limitation to this study is the use of college students, aged 18-20, as participants. The use of college students between 18-20 years of age does not allow for 
generalizability across all age groups. The reason college students in that specific age range were recruited for this study is that they had been in high school less than 4 years prior to the study and had most likely had some contact with at least one pregnant adolescent or adolescent mother in high school. From this contact they will have been able to develop opinions and perceptions about adolescent mothers. They may also have some continuing contact with adolescent mothers and thus their perceptions may be currently influencing the way they interact with these mothers. Participants' answers to the background questionnaire indicate that most of the known mothers (73\%) were friends of the participants. Participants may not have rated the adolescent mothers in this study as negatively as expected because they relate to their friends and would see being disapproving of adolescent mothers as a betrayal to their friend(s).

This limitation brings about a possible future direction for this research. It would be important to know how people of different ages and different cohorts perceive adolescent and out-of-wedlock parenthood. Adolescent parenthood and out-of-wedlock parenthood is more common in the present day United States than in the 1940s through the 1980s (Ventura \& Bachrach, 2000), and even though there is still a stigma attached to having a child at a young age and having a child out of wedlock, the stigma associated with these situations is probably not as dominant as it used to be. Thus, perhaps those of older generations, such as those born in the 1940s, would have much more negative perceptions of adolescent and unmarried mothers than participants born in the 1970s through the 1990s when the incidence of adolescent and out-ofwedlock parenthood was steadily rising (Ventura \& Bachrach).

The perceptions of those of older generations may have a greater influence on presentday adolescent mothers because they are the parents and grandparents of today's adolescent mothers. Those of older generations may have more of an influence on adolescent mothers' lives than do college students between the ages of 18 and 20 because they are more likely providing instrumental and emotional support to the mothers than are the college students. Therefore, if an adolescent mother has parents and grandparents who do not approve of her becoming a mother at such an early age, those parents and grandparents may reject her lifestyle and discontinue any instrumental and emotional support they were providing. Adults ages 18-20 are usually friends to adolescent mothers and are not responsible for providing for them, and thus could not take that instrumental support away if they disapproved of the adolescent becoming a mother. Those 1820-year-old friends could decide to end their friendship with the adolescent mothers if they do 
not approve, but it is easier to find new friends than it would be to find a new parent or grandparent figure. Thus, research in the future should also focus on participants older than 20 years of age because those who are older may influence the lives of adolescent mothers to a much greater degree than those 18-20 years of age.

Another possible limitation of this study relates to the Age Label variable. Perhaps if the study was to include mothers labeled as 16 years old or younger the participants may have perceived them and their infants more negatively than the mothers said to be 17 years of age. There is evidence that older adolescent mothers, in general, are more competent caregivers than young adolescent mothers (Reis, 1989; Secco, Ateah, Woodgate, \& Moffatt, 2002). Perhaps participants believed the adolescent-labeled mothers were mature enough to be able to competently care for a child because they were said to be 17 years of age. The participants in this study were all between the ages of 18 and 20 and were not long ago 17 themselves, so perhaps it was easy for them to think back to when they were 17 and believe that they would have been competent caregivers at that time. If the vignettes included descriptions of mothers who were 14 years old, on the other hand, the participants may have rated them much lower because, in general, 14-year-olds are not as mature as 17-year-olds.

Conclusion. The current study attempted to discover the nature of participants' perceptions of adolescent and adult and unmarried and married mothers. Although only partial support for the research hypotheses was found, the results suggest that, depending on their age and marital status, mothers and their infants are perceived differently. The findings in this study uncovered some instances in which infants of adolescent mothers were thought to have more promising futures than infants of adult mothers and some instances in which married mothers were not perceived to be as well-off as unmarried mothers. In these instances, mothers and their infants may have exceeded the expectations of the participants. Also, as expected, there were instances in which adult and/or married mothers and their infants were believed to better off than adolescent mothers in general, adolescent/married mothers and their infants, and adult/unmarried mothers. In conclusion, although adolescent and unmarried mothers and their infants were not consistently rated more negatively than adult and married mothers and their infants, one cannot conclude that adolescent and unmarried mothers and their infants are thought of as positively as adult and married mothers and their infants. The importance of this study is that it indicates that while there are instances of less positive expectations for adolescent and unmarried mothers and 
their infants, these mothers and infants can also exceed those expectations and cause people to think differently about their situation. In conclusion, it does not appear that mothers and their infant are judged solely on the basis of their situation, but also on their many characteristics. 
References

Alan Guttmacher Institute. (1998). Facts in brief: Teen sex and pregnancy. Retrieved July 20, 2003 from http://www.agi-usa.org/pubs/fb_teen_sex.htm.

Alan Guttmacher Institute. (2004a). U.S. teenage pregnancy statistics with comparative statistics for women aged 20-24 (1972-2000). Retrieved January 31, 2005, from http://www. guttmacher.org/pubs/teen_stats.html.

Alan Guttmacher Institute. (2004b). U.S. teenage pregnancy statistics. Overall trends, trends by Race and ethnicity, and state-by-state information. Retrieved January 31, 2005 from http://www.agi-usa.org/pubs/state_pregnancy_trends.pdf.

Annie E. Casey Foundation. (1998). Kids count special report: When teens have sex: Issues and trends. Baltimore, MD: Annie E. Casey Foundation.

Barratt, M. S. \& Roach, M. A. (1995). Early interactive process: Parenting by adolescent and adult single mothers. Infant Behavior and Development, 18, 97-109.

Bennett Murphey, L. M., Gilliland, K. M., \& Griswold-Rhymer, H. (2001). Unintentional injury among very young children: Differential risk for children of adolescent mothers? Children's Health Care, 30, 293-308.

Biernat, M. \& Dovidio, J. F. (2000). Stigma and stereotypes. In T. F. Heatherton, R. E. Kleck, M. R. Hebl, \& J. G. Hull (Eds.), The social psychology of stigma (pp. 88-125). New York; The Guilford Press.

Black, M. M., Papas, M. A., Hussey, J. M., Hunter, W., Dubowitz, H., Kotch, J. B., et al. (2002). Behavior and development of preschool children born to adolescent mothers: Risk and 3generation households. Pediatrics, 109, 573-580.

Bolton, F. G. (1990). The risk of child maltreatment in adolescent parenting. Advances in Adolescent Mental Health, 4, 223-237.

Bunting, L. \& McAuley, C. (2004). Teenage pregnancy and motherhood: The contribution of support. Child and Family Social Work, 9, 207-215.

Culp, R. E., Appelbaum, M. I., Osofsky, J. D., \& Levy, J. A. (1988). Adolescent and older mothers: Comparison between prenatal maternal variables and newborn interaction measures. Infant Behavior and Development, 11, 353-362. 
Perceptions of Mothers and Infants

Crocker, J., Major, B., \& Steele, C. (1998). Social stigma. In D. T. Gilbert, S. T. Fiske, \& G. Lindzey (Vol. Eds.), The handbook of social psychology (4th ed., pp. 504-553). New York, Oxford University Press.

Crocker, J. \& Quinn, D. M. (2000). Social stigma and the self: Meanings, situations, and selfesteem. In T. F. Heatherton, R. E. Kleck, M. R. Hebl, \& J. G. Hull (Eds.), The social psychology of stigma (pp. 153-183). New York; The Guilford Press.

Darley, J. M. \& Fazio, R. H. (1980). Expectancy confirmation process arising in the social interaction sequence. American Psychologist, 35, 867-881.

Darley, J. M. \& Gross, P. H. (1983). A hypothesis-confirming bias in labeling effects. Journal of Personality and Social Psychology, 44, 20-33.

Elder, G.H. (1974). Role orientation, marital age, and life patterns in adulthood. Merrill-Palmer Quarterly of Behavior and Development, 18, 3-24.

Epps, S. (1993). Effects of labels of infant health and gender on parent ratings of a preterm infant. Children's Health Care, 22, 273-285.

Fernald, C. D., Williams, R. A., \& Droescher, S. D. (1985). Actions speak louder...: Effects of diagnostic labels and child behavior on perceptions of children. Professional Psychology: Research and Practice, 16, 648-660.

Field, T. F., Widmayer, S. M., Stringer, S., \& Ignatoff, E. (1980). Teenage, lower-class, black mothers and their preterm infants: An intervention and developmental follow-up. Child Development, 51, 426-436.

Fiske, S. T. (1998). Stereotyping, prejudice, and discrimination. In D. T. Gilbert, S. T. Fiske, \& G. Lindzey (Vol. Eds.), The handbook of social psychology ( $4^{\text {th }}$ ed., pp. 357-411). New York, Oxford University Press.

French, A. \& Poulsen, J. (2002, September 26). Multivariate analyses of variance (MANOVA). Retrieved March 31, 2005 from http://userwww.sfsu.edu/ efc/classes/biol710/manova/ manova.htm.

Furstenberg, F. F., Jr., Brooks-Gunn, J., \& Morgan, S. P. (1987). Adolescent mothers in later life. Cambridge; Cambridge University Press.

Goffman, E. (1963). Stigma: Notes on the management of spoiled identity. New York: Simon \& Schuster, Inc. 
Hacker, K. A., Amare, Y., Strunk, N., Horst, L. (2000). Listening to youth: Teen perspectives on pregnancy and prevention. Journal of Adolescent Health, 26, 279-288.

Hardy, Welcher, \& Stanley, (1978) Long-range outcome of adolescent pregnancy. Clinical Obstetrics Gynecology, 21, 1215-1232.

Herrmann, M. M., Van Cleve, L., \& Levisen, L. (2001). Parenting competence, social support, and self-esteem in teen mothers case managed by public health nurses. Public Health Nursing, 15, 432-439.

Hubbs-Tait, L., Osofsky, J. D., Hann, D. M., \& McDonald Culp, A. (1994). Predicting behavior problems and social competence in children of adolescent mothers. Family Relations, 43, 439-446.

Hurlburt, N.L. \& McDonald, A. (1997). Adolescent mothers' self-esteem and role identity and their relationship to parenting skills knowledge. Adolescence, 32, 639-654.

Kaiser Family Foundation (1996). Teens say, when it comes to sex information, they need to know more about how to use contraception and prevent sexually transmitted diseases. Retrieved March 26, 2004 from http://www.kff.onlinemagic.net/repro/data/html/ general/teenrel.html.

Karraker, K. H, \& Evans, S. L. (1995). Adolescent mothers' knowledge of child development and expectations for their own infants. Journal of Youth and Adolescence, 25, 651-665.

Leadbeater, B. J., Bishop, S. J., \& Raver, C. C. (1996). Quality of mother-toddler interactions, maternal depressive symptoms and behavior problems in preschoolers of adolescent mothers. Developmental Psychology, 32, 280-288.

Levine, L., Garcia Coll, C. T., \& Oh, W. (1985). Determinants of mother-infant interaction in adolescent mothers. Pediatrics, 75, 23-29.

Lewis, C., Scully, D., \& Condor, S. (1992). Sex stereotyping of infants: A re-examination. Journal of Reproductive and Infant Psychology, 10, 53-61.

Link, B. G. \& Phelan, J. C. (2001). Conceptualizing stigma. Annual Review of Sociology, 27, 363-385.

Luster, T., Bates, L., Fitzgerald, H., Vanderbelt, M., \& Key, J. P. (2000). Factors related to successful outcomes among preschool children born to low-income adolescent mothers. Journal of Marriage and Family, 62, 133-146. 
MacDorman, M. F., Minino, A. M., Strobino, D. M., \& Guyer, B. (2002). Annual summary of vital statistics--2001. Pediatrics, 110, 1037-1052.

Marton, P., Connolly, J., Kutcher, S., \& Korenblum, M. (1993). Cognitive social skills and social self-appraisal in depressed adolescents. Journal of the American Academy of Child and Adolescent Psychiatry, 34, 739-744.

McAnarney, E. R., Lawrence, R. A., Ricciuti, H. N., Polley, J., \& Szilagyi, M. (1986). Interactions of adolescent mothers and their 1-year-old children. Pediatrics, 78, 585-590.

Miller, C. T. \& Kaiser, C. R. (2001). A theoretical perspective on coping with stigma. Journal of Social Issues, 57, 73-92.

National Campaign to Prevent Teen Pregnancy, (February, 2002). Not just another single issue: Teen pregnancy prevention's link to other critical social issues. Retrieved October 23, 2004 from http://www.teenpregnancy.org/resources/data/pdf/notjust.pdf.

Parker, J., G. \& Asher, S., R. (1987). Peer relations and later personal adjustment. Are lowaccepted children at risk? Psychological Bulletin, 102, 357-389.

Price, G. G. \& Gillingham, M. G. (2001). Effects of mothers’ overestimations and underestimations of their children's intellectual ability: A reanalysis of Hunt and Paraskevopoulos. The Journal of Genetic Psychology, 146, 477-481.

Reis, J. (1998). A comparison of young teenage, older teenage, and adult mothers on determinants of parenting. Journal of Psychology: Interdisciplinary \& Applied, 123, 141 151.

Riggs, L, Holmbeck, G., Paikoff, R., \& Bryant, F. B. (2004). Teen mothers parenting their own teen offspring: The moderating role of parenting support. Journal of Early Adolescence, 24, 200-230.

Rosenkrantz Aronson, S. \& Huston, A. C. (2004). The mother-infant relationship in single, cohabiting, and married families: A case for marriage? Journal of Family Psychology, 18, 5-18.

Rutman, D., Strega, S., Callahan, M., \& Dominelli, L. (2002). 'Undeserving' mothers? Practitioners' experiences working with young mothers in/from care. Child and Family Social Work, 7, 149-159. 
Secco, M. L., Ateah, C., Woodgate, R., \& Moffatt, M. E. K. (2002). Perceived and performed infants care competence of younger and older adolescent mothers. Issues in Comprehensive Pediatric Nursing, 25, 97-112.

Smith, P., K. \& Brooks-Gunn, J. (1997). Correlates and consequences of harsh discipline for young children. Archives of Pediatric and Adolescent Medicine, 151, 777-786.

Sommer, K. S., Whitman, T. L., Borkowski, J. G., Gondoli, D. M., Burke, J., Maxwell, S. E., et al. (2000). Prenatal maternal predictors of cognitive and emotional delays in children of adolescent mothers. Adolescence, 35, 87-112.

Spieker, S. J., Larson, N. C., Lewis, S. M., Keller, T. E., \& Gilchrist, L. (1999). Developmental trajectories of disruptive behavior problems in preschool children of adolescent mothers. Child Development, 70, 443-458.

Sroufe, A., L. \& Rutter, M. (1984). The domain of developmental psychopathology. Child Development, 55, 17-29.

Stern, M. \& Hildebrandt, K. A. (1984). Prematurity stereotyping: Effects of labeling on adults' perceptions of infants. Developmental Psychology, 20, 360-362.

Stern, M. \& Hildebrandt, K. A. (1986). Prematurity stereotyping: Effects on mother-infant interaction. Child Development, 57, 308-315.

Stern, M., Karraker, K. H., Sopko, A. M., \& Norman, S. (2000). The prematurity stereotype revisited: Impact on mothers' interactions with premature and full-term infants. Infant Mental Health Journal, 21, 495-509.

Stern, M. \& Karraker, K. H. (1988). Prematurity stereotyping by mothers of premature infants. Journal of Pediatric Psychology, 13, 255-263.

Stern, M. \& Karraker, K. H. (1989). Modifying the prematurity stereotype: The effects of information on negative perceptions of infants. Journal of Social and Clinical Psychology, 8, 1-13.

Stern, M. \& Karraker, K. H. (1992). Modifying the prematurity stereotype in mothers of premature and ill full-term infants. Journal of Clinical Child Psychology, 21, 76-82.

Tabachnik, B. G., \& Fidell, L. S. (2001). Using multivariate statistics (4th ed.). Needham Heights, MA: Allyn and Bacon. 
Tamis-Lemonda, C. S., Shannon, J., \& Spellmann, M. (2002). Low-income adolescent mothers' knowledge about domains of child development. Infant Mental Health Journal, 23, 88103.

Teti, D. M. \& Gelfand, D. M. (1991). Behavioral competence among mothers of infants in the first year: The mediational role of maternal self-efficacy. Child Development,62, 918-929

Vogel, D. A., Lake, M. A., Evans, S., \& Karraker, K. H. (1991). Children's and adults' sexstereotyped perceptions of infants. Sex Roles, 24, 605-616.

Ventura, S. J. \& Bachrach, C.A. (2000). Nonmarital childbearing in the United States, 1940-99. National Vital Statistics Reports, 48. No. 16.

Ventura, S. J., Martin, J. A., Curtin, S. C., \& Mathews, T. J. (1999). Births: final data for 1997. National Vital Statistics Report, 47, No.18.

Vukelich, C. \& Kliman, D. S. (1985). Mature and teenage mothers' infant growth expectations and use of child development information sources. Family Relations, 34, 189-196.

Wakschlag, L. S., Gordon, R., Lahey, B., Loebe, R., Green, S., \& Leventhal, B. (2000). Maternal age at first birth as risk factor for conduct disorder in clinically referred boy. Journal of Research on Adolescence, 10, 417-441.

Warren, N. C. (2005). What is the right age to get married? Retrieved February 28, 2005 from, http://www.mynippon.com/dreamland/marriage-age.htm. 
Table 1

Video Presentation Conditions

Presentation Order

1 2 3 4

1 Adolescent/

1 Adolescent/

1 Adult/ Married

1 Adult/

Married

Unmarried

2 Adolescent/

Unmarried

2 Adult/ Unmarried

2 Adult/ Married

Unmarried

2 Adolescent/

3 Adolescent/

3 Adolescent/ Married

3 Adult/ Unmarried

Married

Unmarried

4 Adult/ Unmarried

4 Adolescent/ Married

3 Adult/ Married

4 Adult/ Married

4 Adolescent/

Unmarried

2 Adolescent/

Married

2 Adolescent/

2 Adult/ Married

2 Adult/

3 Adult/ Unmarried

Unmarried

3 Adolescent/

Unmarried

4 Adolescent/

3 Adult/ Married

Unmarried

3 Adolescent/

Unmarried

4 Adolescent/ Married

4 Adult/ Unmarried

Married

1 Adult/ Married

1 Adolescent/ Married

4 Adult/ Married

1 Adolescent/

Unmarried

3 Adolescent/

3 Adolescent/

3 Adult/ Married

3 Adult/

Married

Unmarried

4 Adolescent/

Unmarried

4 Adult/ Unmarried

4 Adult/ Married

Unmarried

4 Adolescent/

1 Adolescent/

1 Adolescent/ Married

1 Adult/ Unmarried

Married

Unmarried

2 Adult/ Unmarried

2 Adolescent/ Married

2 Adult/ Married

4 Adolescent/

Married

4 Adolescent/

4 Adult/Married

Unmarried

1 Adolescent/

1 Adult/ Married

2 Adolescent/

Unmarried

1 Adult/ Unmarried

1 Adult/ Married

Unmarried

4 Adult/

Unmarried

2 Adolescent/

2 Adolescent/ Married

2 Adult/ Unmarried

1 Adolescent/

Unmarried

3 Adult/ Unmarried

3 Adolescent/ Married

Married

3 Adult/ Married

2 Adult/ Married

3 Adolescent/

Unmarried 
Perceptions of Mothers and Infants 46

Table 2

Multivariate and Univariate Analyses of Variance for Infant Rating Scales (IRS)

Univariate

Multivariate

Overall Future

\begin{tabular}{|c|c|c|c|c|c|c|c|c|c|}
\hline Source & $d f$ & $\Lambda$ & $F^{a}$ & $\eta^{2}$ & $d f$ & $F^{b}$ & $\eta^{2}$ & $F^{b}$ & $\eta^{2}$ \\
\hline Age Label (A) & 2 & 0.98 & 1.16 & & 1 & 0.01 & & 1.78 & \\
\hline Marital Status Label (MS) & 2 & 1.00 & 0.17 & & 1 & 0.00 & & 0.24 & \\
\hline Participant Gender (G) & 2 & 1.00 & 0.05 & & 1 & 0.00 & & 0.07 & \\
\hline Video Number (V) & 6 & 0.64 & $7.98 * *$ & .31 & 3 & $13.97 * *$ & .30 & $3.99 * *$ & .11 \\
\hline A X MS & 2 & 0.94 & $3.20 *$ & .06 & 1 & 0.12 & & 3.59 & \\
\hline A X G & 2 & 0.99 & 0.34 & & 1 & 0.32 & & 0.67 & \\
\hline A X V & 6 & 0.95 & 0.81 & & 3 & 0.07 & & 0.81 & \\
\hline MS X G & 2 & 0.92 & $3.91 *$ & .08 & 1 & 0.11 & & $4.52 *$ & .05 \\
\hline MS X V & 6 & 0.84 & $2.87 *$ & .16 & 3 & 1.49 & & $5.90 * *$ & .16 \\
\hline G X V & 6 & 0.93 & 1.14 & & 3 & 0.06 & & 1.89 & \\
\hline A X MS X G & 2 & 0.99 & 0.37 & & 1 & 0.46 & & 0.67 & \\
\hline A X M S X V & 6 & 0.92 & 1.30 & & 3 & 1.66 & & 2.35 & \\
\hline A X G X V & 6 & 0.86 & $2.46^{*}$ & .11 & 3 & 1.23 & & $3.52 *$ & .10 \\
\hline MS X G X V & 6 & 0.99 & 0.20 & & 3 & 0.12 & & 0.38 & \\
\hline A X MS X G X V & 6 & 0.97 & 0.54 & & 3 & 0.43 & & 0.19 & \\
\hline
\end{tabular}

Note. $\Lambda=$ Wilks's Lambda. $\eta^{2}=$ eta $^{2}$

${ }^{\mathrm{a}}$ Multivariate error $d f=95$. ${ }^{\mathrm{b}}$ Univariate error $d f=96$.

$* p<.05 .{ }^{* *} p<.01$. 
Table 3

Means, Standard Deviations and t-values for IRS Significant Univariate Effects

IRS Scores

\begin{tabular}{|c|c|c|c|c|c|}
\hline \multirow[b]{2}{*}{ Source } & \multicolumn{2}{|c|}{ Overall Mean Score } & \multicolumn{3}{|c|}{ Future Mean Score } \\
\hline & $M$ & $S D$ & $M$ & $S D$ & $t$ \\
\hline \multicolumn{6}{|c|}{ Video Number } \\
\hline V1 & 4.79 & 0.45 & 4.73 & 0.66 & \\
\hline $\mathrm{V} 2$ & 4.50 & 0.67 & 4.83 & 0.90 & \\
\hline V3 & 5.34 & 0.55 & 5.33 & 0.80 & \\
\hline V4 & 5.19 & 0.64 & 4.90 & 0.86 & \\
\hline \multicolumn{6}{|c|}{ Marital Status x Gender } \\
\hline \multicolumn{6}{|l|}{ M } \\
\hline UNM & & & 5.04 & 0.84 & \\
\hline MAR & & & 4.82 & 1.00 & \\
\hline \multicolumn{6}{|l|}{$\mathrm{F}$} \\
\hline UNM & & & 4.79 & 0.86 & \\
\hline MAR & & & 5.14 & 0.72 & \\
\hline \multicolumn{6}{|c|}{ Marital Status x Video } \\
\hline \multicolumn{6}{|c|}{ Number } \\
\hline \multicolumn{6}{|l|}{$\mathrm{V} 1$} \\
\hline UNM & & & 4.76 & 0.69 & \\
\hline MAR & & & 4.69 & 0.66 & \\
\hline \multicolumn{6}{|l|}{$\mathrm{V} 2$} \\
\hline UNM & & & 4.46 & 1.00 & \\
\hline MAR & & & 5.19 & 0.63 & 2.44 \\
\hline \multicolumn{6}{|l|}{ V3 } \\
\hline UNM & & & 5.14 & 0.71 & \\
\hline MAR & & & 5.53 & 0.85 & \\
\hline \multicolumn{6}{|l|}{ V4 } \\
\hline UNM & & & 5.29 & 0.80 & 2.45 \\
\hline MAR & & & 4.51 & 0.98 & \\
\hline
\end{tabular}


Table 3 (continued)

Means, Standard Deviations, and t-values for IRS Significant Univariate Effects

IRS Scores

Overall Mean Score $\quad$ Future Mean Score

\begin{tabular}{|c|c|c|c|c|}
\hline Source & $S D$ & $M$ & $S D$ & $\mathrm{t}$ \\
\hline \multicolumn{5}{|c|}{ Age Label x Gender x Video Number } \\
\hline \multicolumn{5}{|c|}{ V1 } \\
\hline \multicolumn{5}{|l|}{ M } \\
\hline ADOL & & 4.25 & 0.50 & \\
\hline ADLT & & 4.83 & 0.60 & 2.15 \\
\hline \multicolumn{5}{|l|}{$\mathrm{F}$} \\
\hline ADOL & & 5.13 & 0.33 & \\
\hline ADLT & & 4.69 & 0.68 & \\
\hline \multicolumn{5}{|l|}{$\mathrm{V} 2$} \\
\hline \multicolumn{5}{|l|}{$\mathrm{M}$} \\
\hline ADOL & & 4.78 & 0.84 & \\
\hline ADLT & & 4.75 & 0.89 & \\
\hline \multicolumn{5}{|l|}{$\mathrm{F}$} \\
\hline ADOL & & 4.53 & 0.80 & \\
\hline ADLT & & 5.25 & 0.85 & \\
\hline \multicolumn{5}{|l|}{ V3 } \\
\hline \multicolumn{5}{|l|}{$\mathrm{M}$} \\
\hline ADOL & & 5.95 & 0.64 & 2.25 \\
\hline ADLT & & 5.20 & 0.94 & \\
\hline \multicolumn{5}{|l|}{$\mathrm{F}$} \\
\hline ADOL & & 5.19 & 0.61 & \\
\hline ADLT & & 5.35 & 0.42 & \\
\hline \multicolumn{5}{|l|}{ V4 } \\
\hline \multicolumn{5}{|l|}{ M } \\
\hline ADOL & & 4.60 & 1.39 & \\
\hline ADLT & & 5.08 & 0.44 & \\
\hline \multicolumn{5}{|l|}{$\mathrm{F}$} \\
\hline ADOL & & 5.19 & 0.73 & \\
\hline ADLT & & 5.08 & 0.59 & \\
\hline
\end{tabular}

Note. Highlighted means in each comparison indicate more positive ratings. Independent samples t-test were not run on Video Number; see Table 4 for Bonferonni post-hoc tests of Video Number. 
Table 4

Means and Standard Deviations for Video Number Main Effects

\begin{tabular}{|c|c|c|c|c|c|c|c|c|}
\hline \multirow[b]{2}{*}{ Measure } & \multicolumn{2}{|c|}{ Video 1} & \multicolumn{2}{|l|}{ Video 2} & \multicolumn{2}{|l|}{ Video 3} & \multicolumn{2}{|l|}{ Video 4} \\
\hline & $M$ & $S D$ & $M$ & $S D$ & $M$ & $S D$ & $M$ & $S D$ \\
\hline \multicolumn{9}{|l|}{ IRS } \\
\hline Overall & $4.79_{\mathrm{a}, \mathrm{b}}$ & 0.45 & $4.50_{c, d}$ & 0.67 & $5.34_{\mathrm{a}, \mathrm{c}}$ & 0.55 & $5.19_{b, d}$ & 0.52 \\
\hline Future & $4.73 \mathrm{a}$ & 0.66 & 4.83 & 0.90 & $5.33 \mathrm{a}$ & 0.80 & 4.90 & 0.96 \\
\hline \multicolumn{9}{|l|}{ MRS } \\
\hline Responsiveness & $5.34_{\mathrm{a}}$ & 0.85 & 5.73 & 0.76 & $6.05_{\mathrm{a}, \mathrm{b}}$ & 0.65 & $5.30_{\mathrm{b}}$ & 0.96 \\
\hline Sociability & $4.42_{\mathrm{a}}$ & 1.11 & $5.09_{b}$ & 1.09 & $5.91_{\mathrm{a}, \mathrm{b}, \mathrm{c}}$ & 0.81 & $5.04 \mathrm{c}$ & 1.08 \\
\hline Physical Appearance & $4.03_{\mathrm{a}, \mathrm{b}}$ & 1.04 & $5.41_{\mathrm{a}, \mathrm{c}}$ & 0.88 & $5.80_{b, d}$ & 0.87 & $4.63_{c, d}$ & 1.03 \\
\hline Intelligence & 4.75 & 0.99 & 5.09 & 1.16 & 5.32 & 0.75 & 4.72 & 1.18 \\
\hline Future & $4.41_{\mathrm{a}}$ & 0.97 & 4.79 & 1.08 & $5.34_{a, b}$ & 0.97 & $4.53 \mathrm{~b}$ & 1.29 \\
\hline \multicolumn{9}{|l|}{ IIRS } \\
\hline Overall & $4.68_{\mathrm{a}, \mathrm{b}}$ & 0.82 & $4.24_{\mathrm{c}, \mathrm{d}}$ & 0.98 & $5.93_{\mathrm{a}, \mathrm{c}}$ & 0.52 & $5.49_{b, d}$ & 0.66 \\
\hline Liking & $5.34_{\mathrm{a}}$ & 1.04 & $4.72_{b, c}$ & 1.28 & $6.44_{\mathrm{a}, \mathrm{b}}$ & 0.72 & $5.91_{\mathrm{c}}$ & 0.73 \\
\hline \multicolumn{9}{|l|}{ MIRS } \\
\hline Overall & $5.29 \mathrm{a}$ & 0.86 & 5.85 & 0.74 & $6.40_{\mathrm{a}, \mathrm{b}}$ & 0.71 & $5.42 \mathrm{~b}$ & 1.19 \\
\hline Liking & $4.25 \mathrm{a}$ & 1.78 & 5.31 & 1.42 & $5.50_{\mathrm{a}}$ & 2.17 & 4.91 & 1.73 \\
\hline
\end{tabular}

Note. Means in the same row with the same subscripts are significantly different, $\mathrm{p}<.05$. 
Table 5

Multivariate and Univariate Analyses of Variance for Mother Rating Scales (MRS)

Univariate

\begin{tabular}{|c|c|c|c|c|c|c|c|c|c|c|c|c|c|c|c|}
\hline \multirow[b]{3}{*}{ Source } & & & & & \\
\hline & & & & & \multicolumn{3}{|c|}{ Responsiveness } & \multicolumn{2}{|c|}{ Sociability } & \multicolumn{2}{|c|}{$\begin{array}{c}\text { Physical } \\
\text { Appearance }\end{array}$} & \multicolumn{2}{|c|}{ Intelligence } & \multicolumn{2}{|c|}{ Future } \\
\hline & $d f$ & $\Lambda$ & $F^{a}$ & $\eta^{2}$ & $d f$ & $F^{b}$ & $\eta^{2}$ & $F^{b}$ & $\eta^{2}$ & $F^{b}$ & $\eta^{2}$ & $F^{b}$ & $\eta^{2}$ & $F^{b}$ & $\eta^{2}$ \\
\hline Age Label (A) & 5 & 0.95 & 1.00 & & 1 & 0.73 & & 0.14 & & 0.67 & & 2.37 & & 1.96 & \\
\hline Participant gender $(\mathrm{G})$ & 5 & 0.96 & 0.77 & & 1 & 0.11 & & 0.74 & & 0.00 & & 0.28 & & 0.03 & \\
\hline Video Number (V) & 15 & 0.42 & $6.30 * *$ & .25 & 3 & $5.58 * *$ & .15 & $10.12 * *$ & .24 & $21.10^{* *}$ & .40 & 2.42 & & $4.93 * *$ & .13 \\
\hline A X MS & 5 & 0.86 & $2.97 *$ & .15 & 1 & 0.02 & & 0.83 & & 0.57 & & $4.89^{*}$ & .05 & $6.67 *$ & .07 \\
\hline MS X G & 5 & 0.94 & 1.10 & & 1 & 0.02 & & 0.03 & & 0.77 & & 0.85 & & 2.26 & \\
\hline MS X V & 15 & 0.92 & 0.49 & & 3 & 0.19 & & 0.65 & & 0.19 & & 1.04 & & 0.84 & \\
\hline G X V & 15 & 0.82 & 1.29 & & 3 & 0.40 & & 0.12 & & 1.28 & & 0.18 & & 0.96 & \\
\hline
\end{tabular}


Table 5 (continued)

Multivariate and Univariate Analyses of Variance for Mother Rating Scales

\begin{tabular}{|c|c|c|c|c|c|c|c|c|c|c|c|c|}
\hline \multirow[b]{3}{*}{ Source } & & & & & \multicolumn{8}{|c|}{ Univariate } \\
\hline & & & & & \multicolumn{3}{|c|}{ Responsiveness } & Sociability & $\begin{array}{c}\text { Physical } \\
\text { Appearance }\end{array}$ & Intelligence & \multicolumn{2}{|l|}{ Future } \\
\hline & $d f$ & $\Lambda$ & $F^{a}$ & $\eta^{2}$ & $d f$ & $F^{b}$ & $\eta^{2}$ & $F^{b}$ & $F^{b}$ & $\eta^{2}$ & $F^{b}$ & $\eta^{2}$ \\
\hline A X M S X V & 15 & 0.87 & 0.87 & & 3 & 0.86 & & 0.80 & 0.08 & 1.02 & 1.32 & \\
\hline A X G X V & 15 & 0.82 & 1.28 & & 3 & 2.36 & & 1.84 & 0.95 & 0.81 & 1.76 & \\
\hline MS X G X V & 15 & 0.89 & 0.74 & & 3 & 0.46 & & 0.50 & 1.53 & 0.22 & 0.24 & \\
\hline
\end{tabular}

Note. $\Lambda=$ Wilks's Lambda.. $\eta^{2}=$

eta $^{2}$

${ }^{a}$ Multivariate error $\mathrm{df}=92 .{ }^{\mathrm{b}}$ Univariate error $\mathrm{df}=96$.

${ }^{*} p<.05 .{ }^{* *} p<.01$. 
Table 6

Means, Standard Deviations, and t-values for MRS Significant Univariate Effects

MRS Scores

\begin{tabular}{|c|c|c|c|c|c|c|c|c|c|c|c|c|}
\hline \multirow[b]{2}{*}{ Source } & \multicolumn{2}{|c|}{ Responsiveness } & \multicolumn{2}{|c|}{ Sociability } & \multicolumn{2}{|c|}{ Physical } & \multicolumn{2}{|c|}{ Intelligence } & \multirow[b]{2}{*}{$t$} & \multicolumn{2}{|l|}{ Future } & \multirow[b]{2}{*}{$t$} \\
\hline & $\mathrm{M}$ & SD & $\mathrm{M}$ & $\mathrm{SD}$ & $\mathrm{M}$ & SD & $\mathrm{M}$ & SD & & $\mathrm{M}$ & SD & \\
\hline \multicolumn{13}{|c|}{ Video Number } \\
\hline V1 & 5.34 & 0.85 & 4.42 & 1.11 & 4.03 & 1.04 & & & & 4.41 & 0.97 & \\
\hline $\mathrm{V} 2$ & 5.73 & 0.76 & 5.09 & 1.09 & 5.41 & 0.87 & & & & 4.79 & 1.08 & \\
\hline V3 & 6.05 & 0.65 & 5.91 & 0.81 & 5.80 & 0.87 & & & & 5.34 & 0.97 & \\
\hline V4 & 5.30 & 0.96 & 5.04 & 1.08 & 4.63 & 1.03 & & & & 4.53 & 1.28 & \\
\hline \multicolumn{13}{|c|}{ Age x Marital Status } \\
\hline \multicolumn{13}{|c|}{ UNM } \\
\hline ADOL & & & & & & & 5.02 & 1.15 & & 4.69 & 1.14 & \\
\hline ADLT & & & & & & & 4.90 & 0.94 & & 4.48 & 0.94 & \\
\hline \multicolumn{13}{|l|}{ MAR } \\
\hline ADOL & & & & & & & 4.64 & 1.11 & & 4.58 & 1.28 & \\
\hline ADLT & & & & & & & 5.33 & 0.91 & 2.75 & 5.32 & 0.98 & 2.59 \\
\hline
\end{tabular}

Note. Highlighted means in each comparison indicate more positive ratings. Independent samples t-test were not run on Video Number; see Table 4 for Bonferonni post-hoc tests of Video Number. 
Table 7

Multivariate and Univariate Analyses of Variance for Infant Interaction Rating Scales (IIRS)

Univariate

Multivariate

Overall

Liking

\begin{tabular}{|c|c|c|c|c|c|c|c|c|c|}
\hline Source & $d f$ & $\Lambda$ & $F^{a}$ & $\eta^{2}$ & $d f$ & $F^{b}$ & $\eta^{2}$ & $F^{b}$ & $\eta^{2}$ \\
\hline Age Label (A) & 2 & 0.96 & 1.84 & & 1 & 3.05 & & 0.39 & \\
\hline Marital Status Label (MS) & 2 & 1.00 & 0.05 & & 1 & 0.08 & & 0.07 & \\
\hline Participant Gender (G) & 2 & 1.00 & 0.24 & & 1 & 0.05 & & 0.39 & \\
\hline Video Number(V) & 6 & 0.49 & $13.41 * *$ & .30 & 3 & $31.49 * *$ & .50 & $17.89 * *$ & .36 \\
\hline A X MS & 2 & 0.99 & 0.55 & & 1 & 0.30 & & 0.07 & \\
\hline A X G & 2 & 0.99 & 0.46 & & 1 & 0.89 & & 0.65 & \\
\hline A X V & 6 & 0.84 & $2.90 * *$ & .08 & 3 & 0.43 & & 2.59 & \\
\hline MS X G & 2 & 0.94 & $3.10^{*}$ & .06 & 1 & 1.31 & & 0.65 & \\
\hline MS X V & 6 & 0.98 & 0.31 & & 3 & 0.56 & & 0.35 & \\
\hline G X V & 6 & 0.98 & 0.40 & & 3 & 0.17 & & 0.12 & \\
\hline A X MS X G & 2 & 0.98 & 1.11 & & 1 & 0.51 & & 0.20 & \\
\hline A X M S X V & 6 & 0.95 & 0.91 & & 3 & 1.61 & & 0.61 & \\
\hline A X G X V & 6 & 0.91 & 1.49 & & 3 & 1.80 & & 2.33 & \\
\hline MS X G X & 6 & 0.97 & 0.53 & & 3 & 1.00 & & 0.41 & \\
\hline A X MS X G X V & 6 & 0.92 & 1.39 & & 3 & 0.89 & & 0.48 & \\
\hline
\end{tabular}

Note. $\Lambda=$ Wilks's Lambda. . $\eta^{2}=$ eta $^{2}$

${ }^{\mathrm{a}}$ Multivariate error $d f=95 .{ }^{\mathrm{b}}$ Univariate error $d f=96$.

$* p<.05 . * * p<.01$. 
Perceptions of Mothers and Infants 54

Table 8

Means and Standard Deviations for IIRS Significant Univariate Effects

IIRS Scores

\begin{tabular}{lllll} 
& \multicolumn{2}{l}{ Overall Mean Score } & \multicolumn{2}{l}{ Liking Rating } \\
\cline { 2 - 5 } Source & $M$ & $S D$ & $M$ & $S D$ \\
\hline & & & & \\
Video Number & 4.68 & 0.82 & 5.34 & 1.04 \\
V1 & 4.24 & 0.98 & 4.72 & 1.28 \\
V2 & 5.93 & 0.52 & 6.44 & 0.72 \\
V3 & 5.49 & 0.66 & 5.91 & 0.73 \\
V4 & & & & \\
\hline
\end{tabular}

Note. Highlighted means in each comparison indicate more positive ratings. Independent samples t-test were not run on Video Number; see Table 4 for Bonferonni post-hoc tests of Video Number. 
Table 9

Multivariate and Univariate Analyses of Variance for Mother Interaction Rating Scales (MIRS)

Univariate

Multivariate Overall Liking

\begin{tabular}{|c|c|c|c|c|c|c|c|c|c|}
\hline Source & $d f$ & $\Lambda$ & $F^{a}$ & $\eta^{2}$ & $d f$ & $F^{b}$ & $\eta^{2}$ & $F^{b}$ & $\eta^{2}$ \\
\hline Age Label (A) & 2 & 0.94 & $3.80 *$ & .06 & 1 & 2.78 & & $4.82 *$ & .15 \\
\hline Marital Status Label (MS) & 2 & 0.93 & $3.36^{*}$ & .07 & 1 & 0.24 & & $4.82 *$ & .15 \\
\hline Participant Gender (G) & 2 & 0.98 & 0.95 & & 1 & 0.44 & & 1.90 & \\
\hline Video Number(V) & 6 & 0.75 & $4.81 * *$ & .13 & 3 & $9.10 * *$ & .22 & $3.27 *$ & .09 \\
\hline A X MS & 2 & 0.96 & 2.18 & & 1 & 0.44 & & $4.38 * * *$ & .04 \\
\hline A X G & 2 & 1.00 & 0.17 & & 1 & 0.09 & & 0.13 & \\
\hline A X V & 6 & 0.97 & 0.53 & & 3 & 0.49 & & 0.71 & \\
\hline MS X G & 2 & 1.00 & 0.05 & & 1 & 0.07 & & 0.00 & \\
\hline MS X V & 6 & 0.96 & 0.73 & & 3 & 0.56 & & 0.62 & \\
\hline G X V & 6 & 0.94 & 1.05 & & 3 & 0.44 & & 1.01 & \\
\hline A X MS X G & 2 & 0.99 & 0.42 & & 1 & 0.51 & & 0.20 & \\
\hline A X M S X V & 6 & 0.95 & 0.84 & & 3 & 1.61 & & 0.61 & \\
\hline A X G X V & 6 & 0.92 & 1.33 & & 3 & 1.50 & & 2.06 & \\
\hline MS X G X V & 6 & 0.98 & 0.41 & & 3 & 0.46 & & 0.21 & \\
\hline $\mathrm{A} X \mathrm{MS} \times \mathrm{G} \times \mathrm{V}$ & 6 & 0.97 & 0.57 & & 3 & 0.11 & & 1.04 & \\
\hline
\end{tabular}

Note. $\Lambda=$ Wilks's Lambda. . $\eta^{2}=$ eta $^{2}$

${ }^{\mathrm{a}}$ Multivariate error $d f=95 .{ }^{\mathrm{b}}$ Univariate error $d f=96$.

$* p<.05 .{ }^{* *} p<.01$. ${ }^{* * *}$ Significant at $p<.05$, but not discussed in the text because the multivariate test is not significant. 
Table 10

Means, Standard Deviations, and t-values for MIRS Significant Univariate Effects

MIRS Scores

\begin{tabular}{|c|c|c|c|c|c|}
\hline \multirow[b]{3}{*}{ Source } & & & & & \\
\hline & \multicolumn{2}{|c|}{ Overall Mean Score } & \multicolumn{3}{|c|}{ Liking Rating } \\
\hline & $M$ & $S D$ & $M$ & $S D$ & $t$ \\
\hline \multicolumn{6}{|c|}{ Age Label } \\
\hline ADOL & & & 4.66 & 1.90 & \\
\hline ADLT & & & 5.33 & 1.72 & 2.09 \\
\hline \multicolumn{6}{|c|}{ Marital Status Label } \\
\hline UNM & & & 5.33 & 1.66 & 2.09 \\
\hline MAR & & & 4.66 & 1.95 & \\
\hline \multicolumn{6}{|c|}{ Video Number } \\
\hline $\mathrm{V} 1$ & 5.29 & 0.86 & 4.25 & 1.78 & \\
\hline $\mathrm{V} 2$ & 5.85 & 0.73 & 5.31 & 1.42 & \\
\hline V3 & 6.40 & 0.71 & 5.50 & 2.17 & \\
\hline V4 & 5.42 & 1.19 & 4.91 & 1.73 & \\
\hline
\end{tabular}

Note. Highlighted means in each comparison indicate more positive ratings. Independent samples t-test were not run on Video Number; see Table 4 for Bonferonni post-hoc tests of Video Number. 
Table 11

F-statistics, Means, and Standard Deviations for Significant Individual Items in the IRS with Video Effects

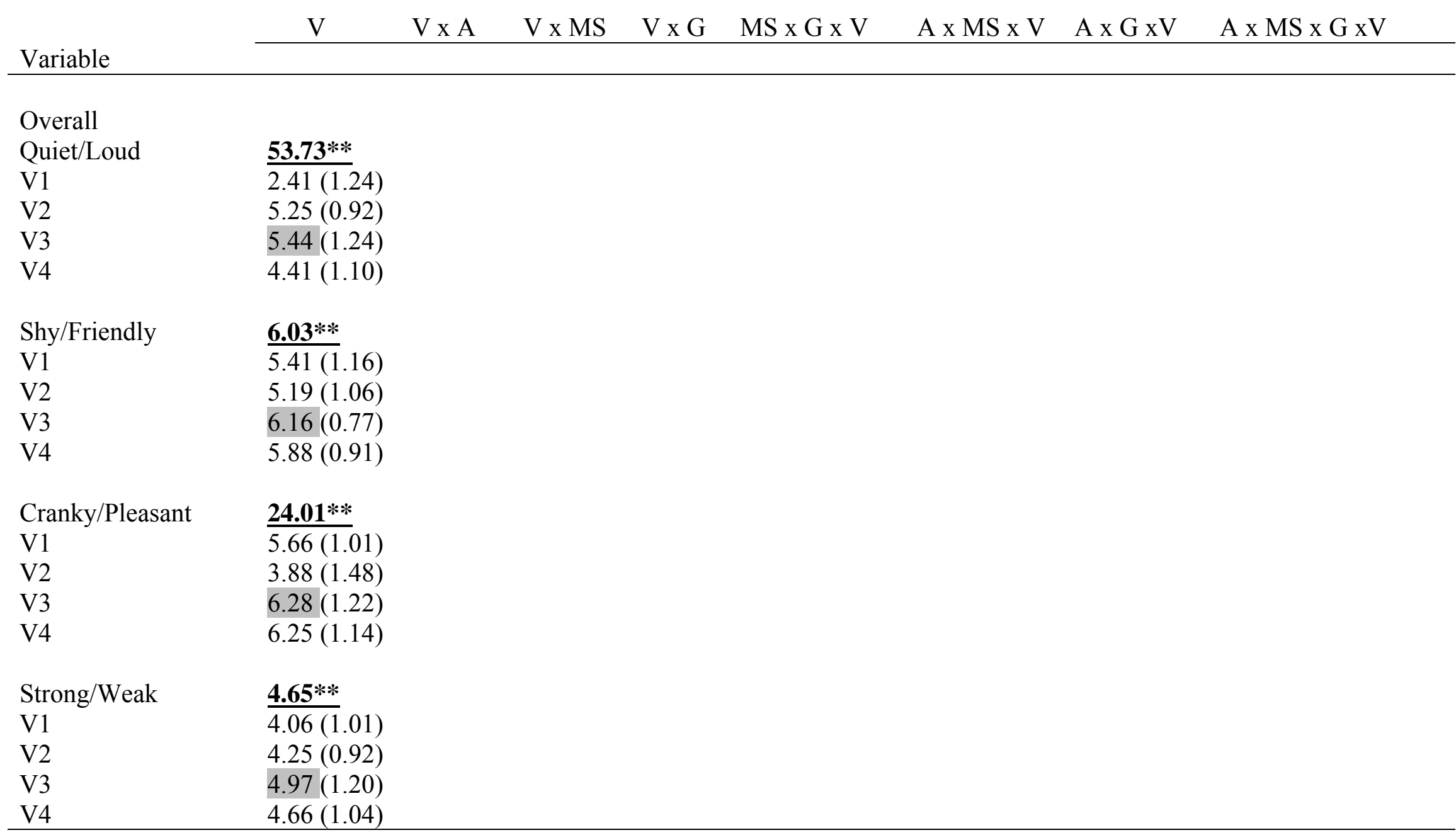


Table 11 (continued)

F-statistics, Means, and Standard Deviations for Significant Individual Items in the IRS with Video Effects

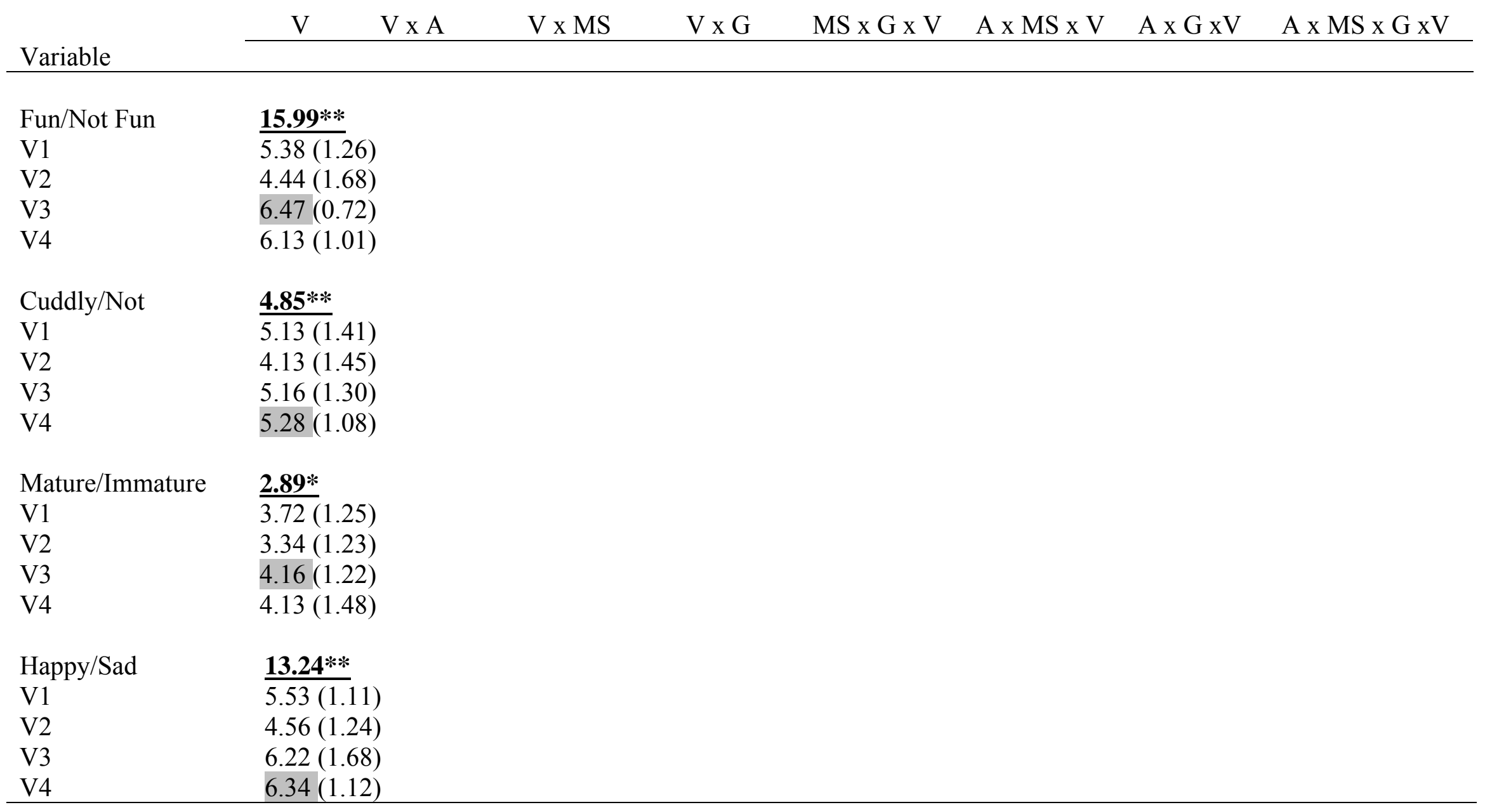


Table 11 (continued)

F-statistics, Means, and Standard Deviations for Significant Individual Items in the IRS with Video Effects

\begin{tabular}{|c|c|c|c|c|c|c|c|c|}
\hline \multirow[b]{2}{*}{ Variable } & $\mathrm{V}$ & $\mathrm{V} \times \mathrm{A}$ & $\mathrm{V} \times \mathrm{MS}$ & $\mathrm{Vx} G$ & MS x G x V & $\mathrm{A} \times \mathrm{MS} \times \mathrm{V}$ & $\mathrm{A} \times \mathrm{G} \times \mathrm{V}$ & $\mathrm{A} \times \mathrm{MS} \times \mathrm{G} \times \mathrm{V}$ \\
\hline & & & & & & & & \\
\hline Well Behaved/Not & $\underline{5.70 * *}$ & & & & & & & \\
\hline V1 & $5.63(1.36)$ & & & & & & & \\
\hline V2 & $4.53(1.34)$ & & & & & & & \\
\hline V3 & $5.56(1.34)$ & & & & & & & \\
\hline V4 & $5.75(1.19)$ & & & & & & & \\
\hline Coordinated/Not & $\underline{4.83 * *}$ & & & & & & & \\
\hline V1 & $\overline{4.25(1.32)}$ & & & & & & & \\
\hline V2 & $4.50(1.37)$ & & & & & & & \\
\hline V3 & $5.25(1.19)$ & & & & & & & \\
\hline V4 & $5.25(0.95)$ & & & & & & & \\
\hline \multicolumn{9}{|l|}{ Competent/ } \\
\hline Incompetent & $\underline{4.95 * *}$ & & & & & & & \\
\hline V1 & $4.44(1.13)$ & & & & & & & \\
\hline V2 & $4.78(0.98)$ & & & & & & & \\
\hline V3 & $5.25(0.88)$ & & & & & & & \\
\hline V4 & $5.28(0.99)$ & & & & & & & \\
\hline \multicolumn{9}{|l|}{ Future } \\
\hline Happy/Unhappy & $\underline{4.45^{* *}}$ & & & & & & & \\
\hline $\mathrm{V} 1$ & $\overline{5.06(1.16)}$ & & & & & & & \\
\hline V2 & $5.09(1.09)$ & & & & & & & \\
\hline V3 & $5.88(0.71)$ & & & & & & & \\
\hline V4 & $5.31(1.20)$ & & & & & & & \\
\hline
\end{tabular}


Table 11 (continued)

F-statistics, Means, and Standard Deviations for Significant Individual Items in the IRS with Video Effects

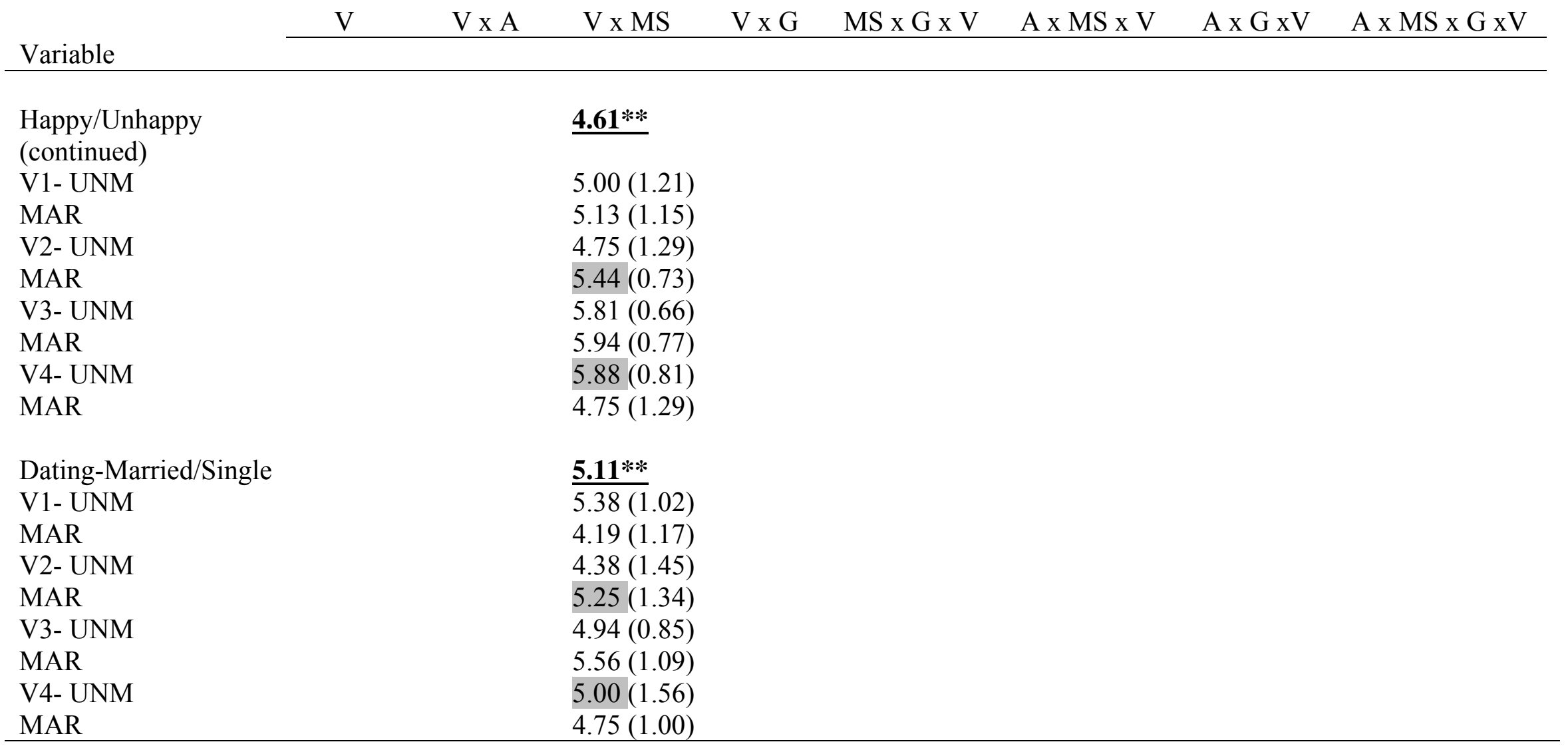


Table 11 (continued)

F-statistics, Means, and Standard Deviations for Significant Individual Items in the IRS with Video Effects

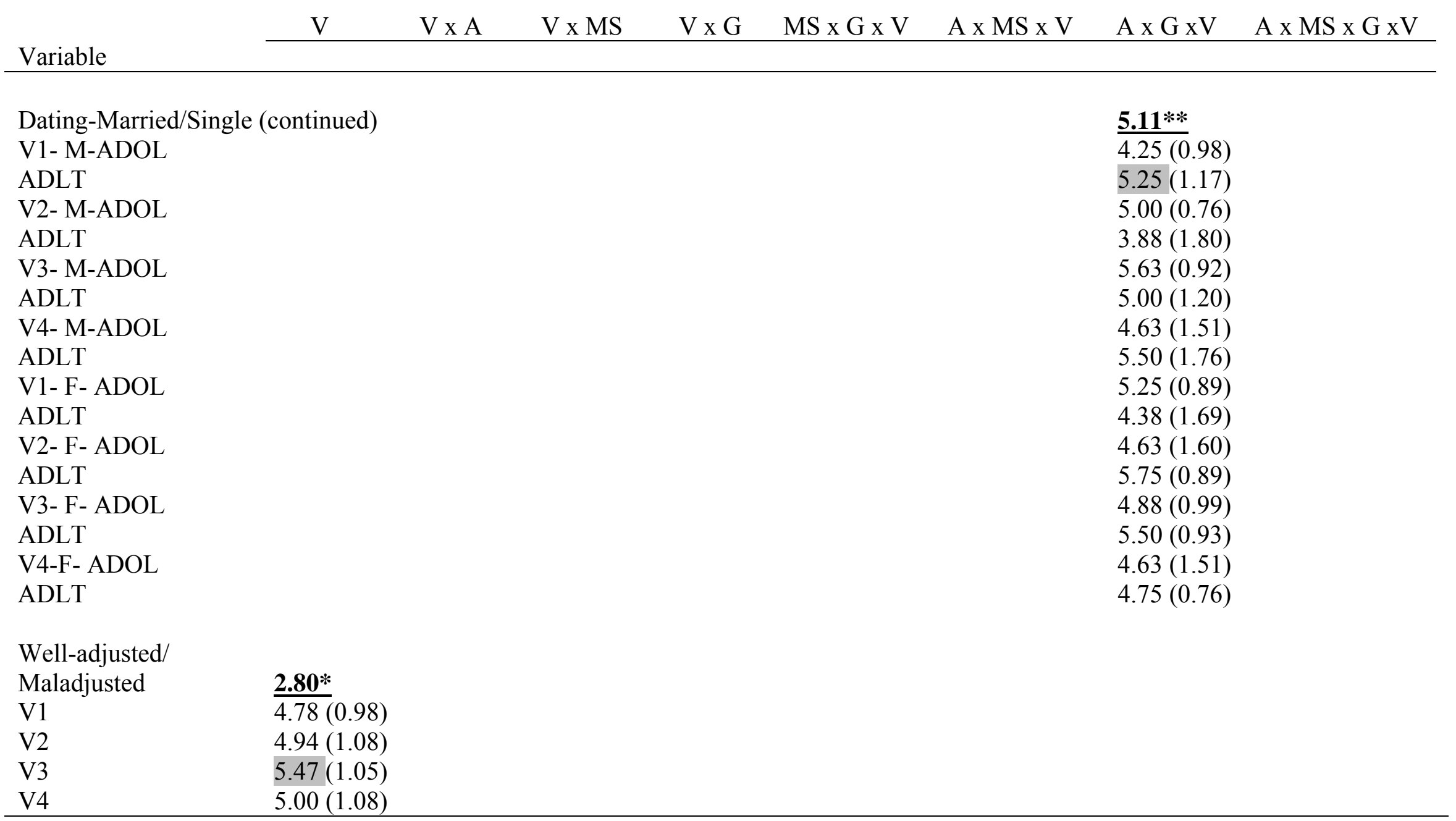


Table 11 (continued)

F-statistics, Means, and Standard Deviations for Significant Individual Items in the IRS with Video Effects

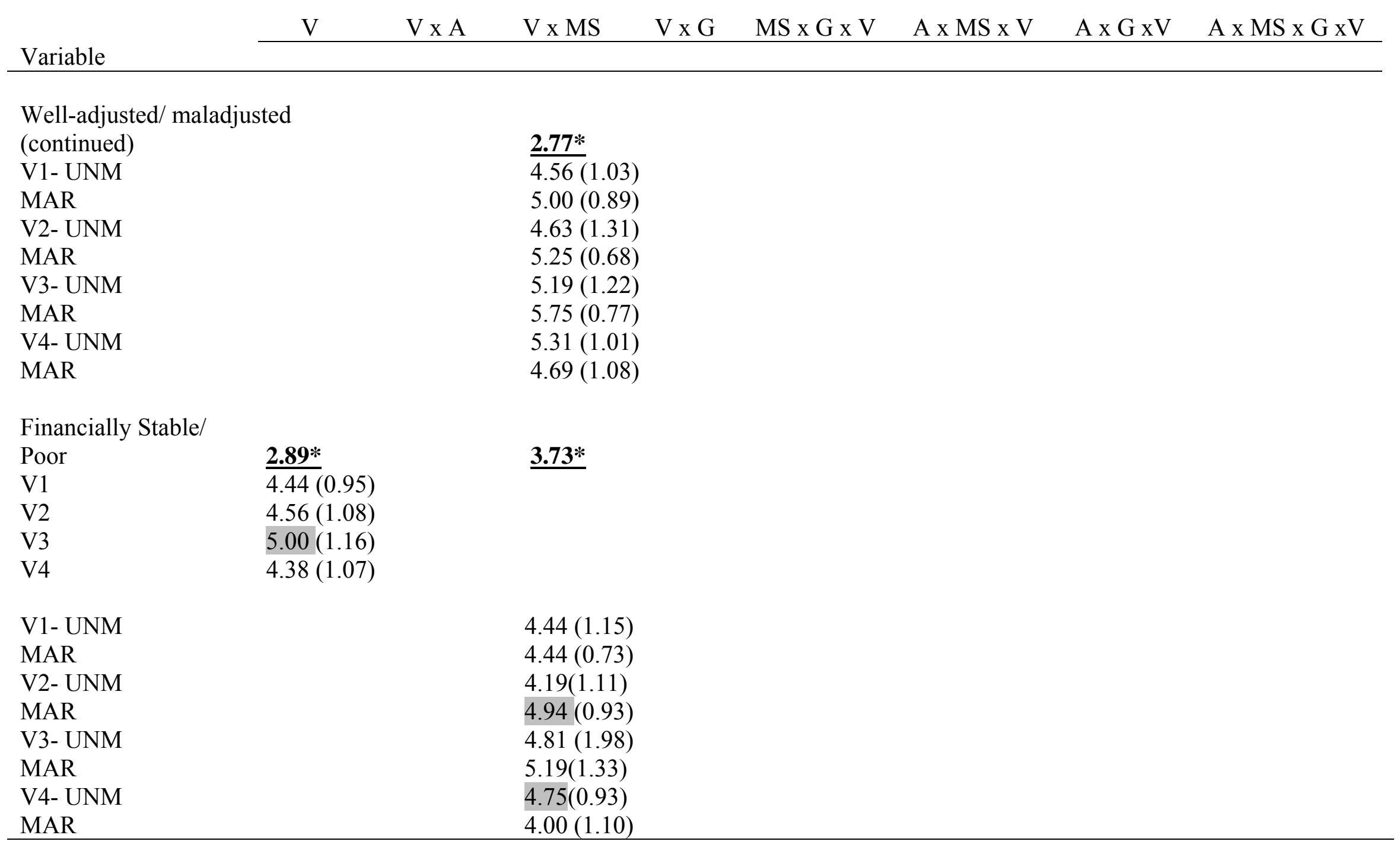


Table 11 (continued)

F-statistics, Means, and Standard Deviations for Significant Individual Items in the IRS with Video Effects

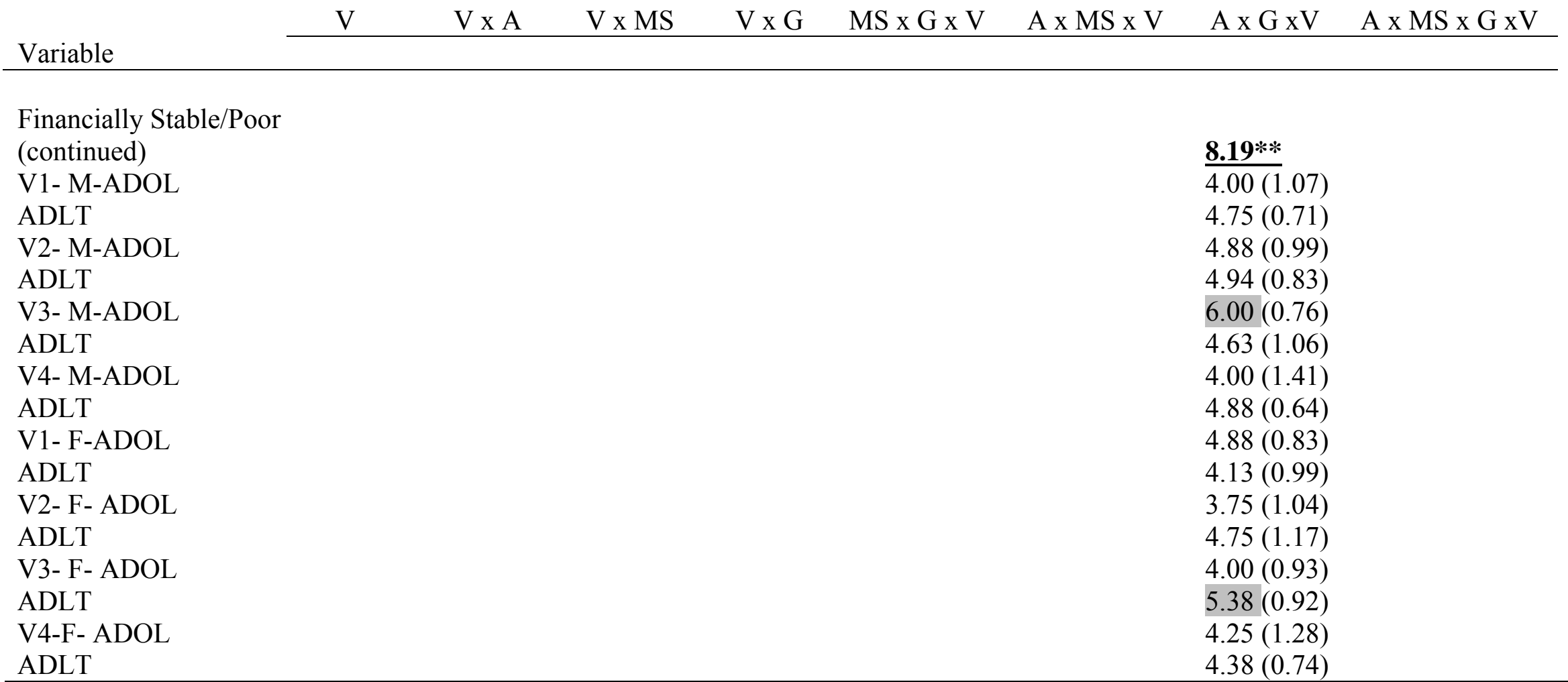

Note. $\mathrm{A}=$ Age Label, MS $=$ Marital Status Label, $\mathrm{G}=$ Participant Sex, $\mathrm{V}=$ Video Number.

$F$ statistics are in bold and are underlined. Means are followed by standard deviations in parentheses. Highlighted means in each comparison indicate more positive ratings. When no mean in a comparison is highlighted, the means are equal.

$* p<.05, * * p<.01$. 
Table 12

F-statistics, Means, and Standard Deviations for Significant Individual Items in the MRS without Video Effects

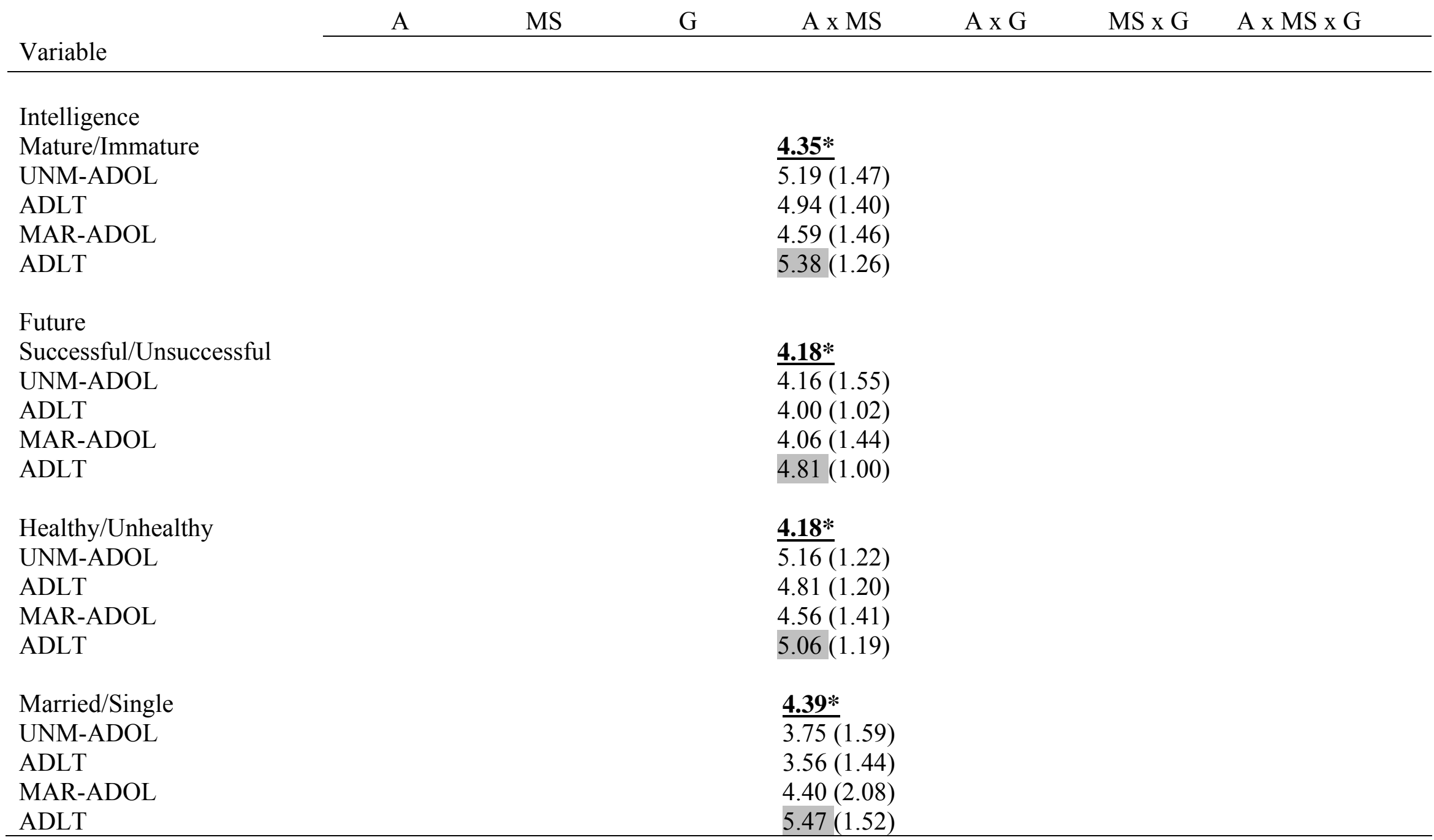


Table 12 (continued)

F-statistics, Means, and Standard Deviations for Significant Individual Items in the MRS without Video Effects

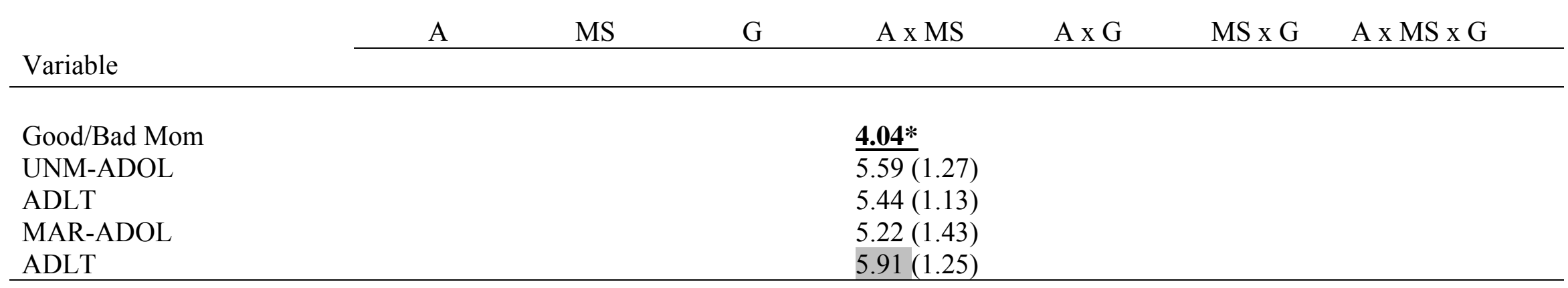

Note. $\mathrm{A}=$ Age Label, MS $=$ Marital Status Label, $\mathrm{G}=$ Participant Sex.

$F$ statistics are in bold and are underlined. Means are followed by standard deviations in parentheses. Highlighted numbers in each comparison indicate more positive ratings.

$* p<.05, * * p<.01$ 
Table 13

F-statistics, Means, and Standard Deviations for Significant Individual Items in the MRS with Video Effects

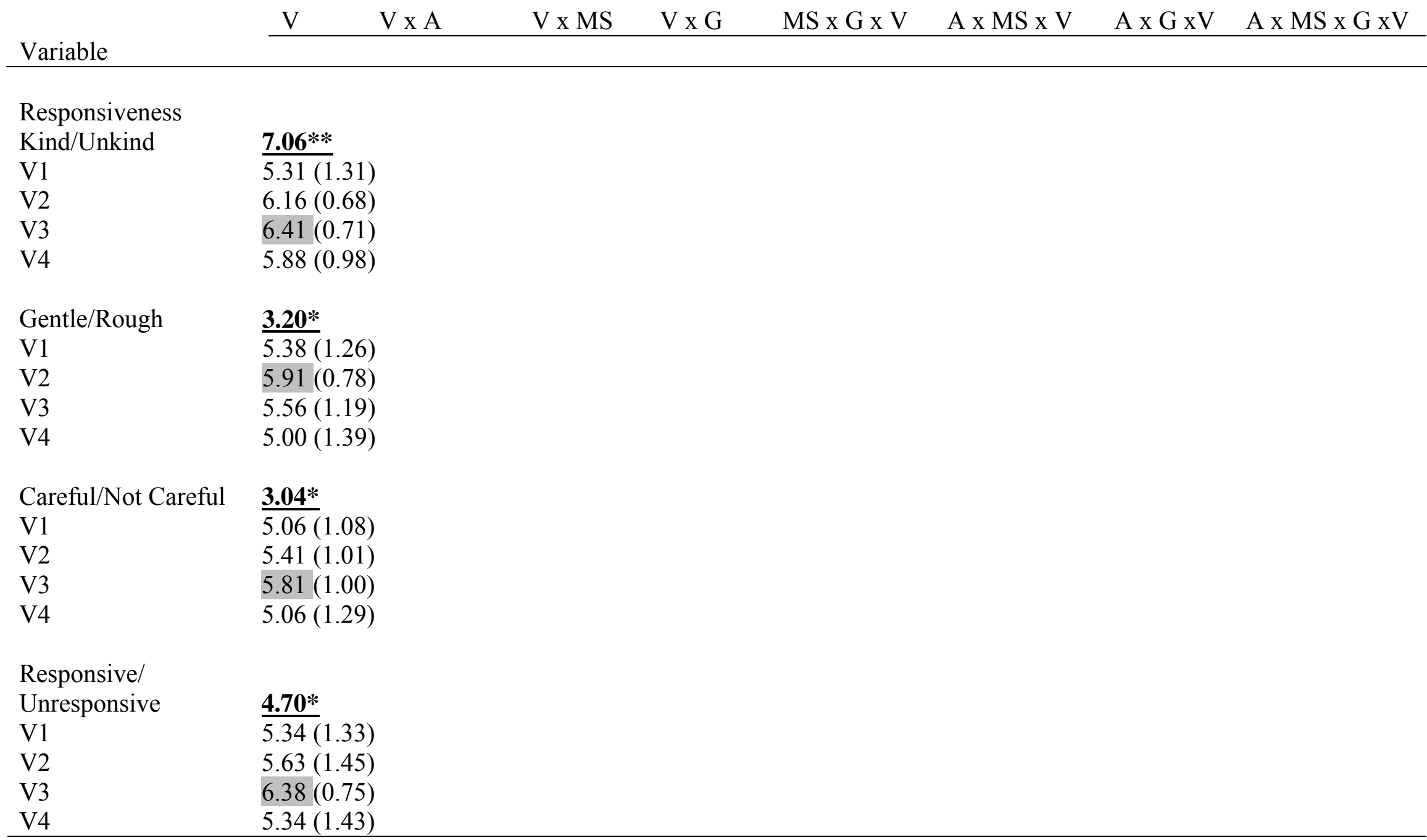


Table 13 (continued)

F-statistics, Means, and Standard Deviations for Significant Individual Items in the MRS with Video Effects

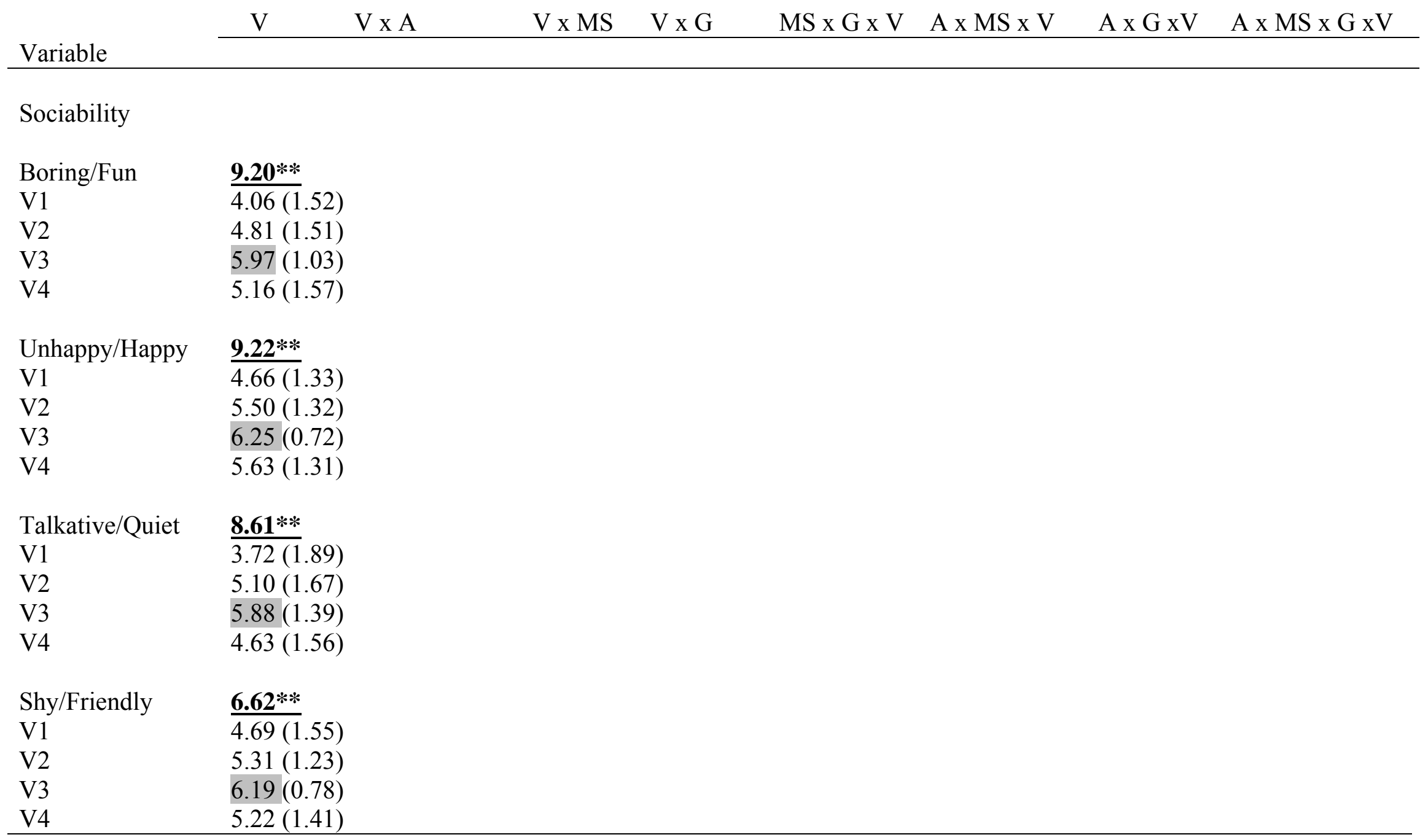


Table 13 (continued)

F-statistics, Means, and Standard Deviations for Significant Individual Items in the MRS with Video Effects

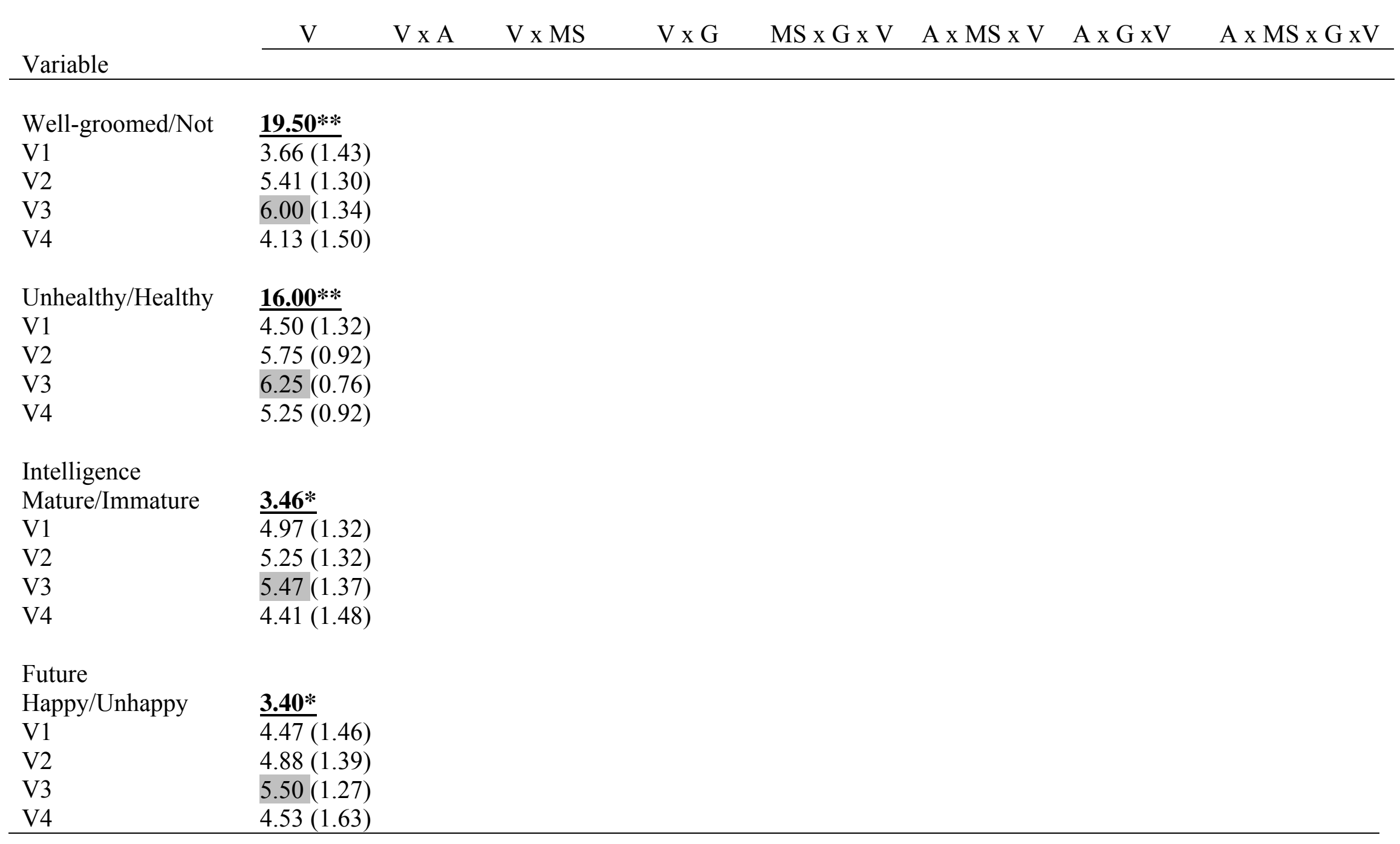


Table 13 (continued)

F-statistics, Means, and Standard Deviations for Significant Individual Items in the MRS with Video Effects

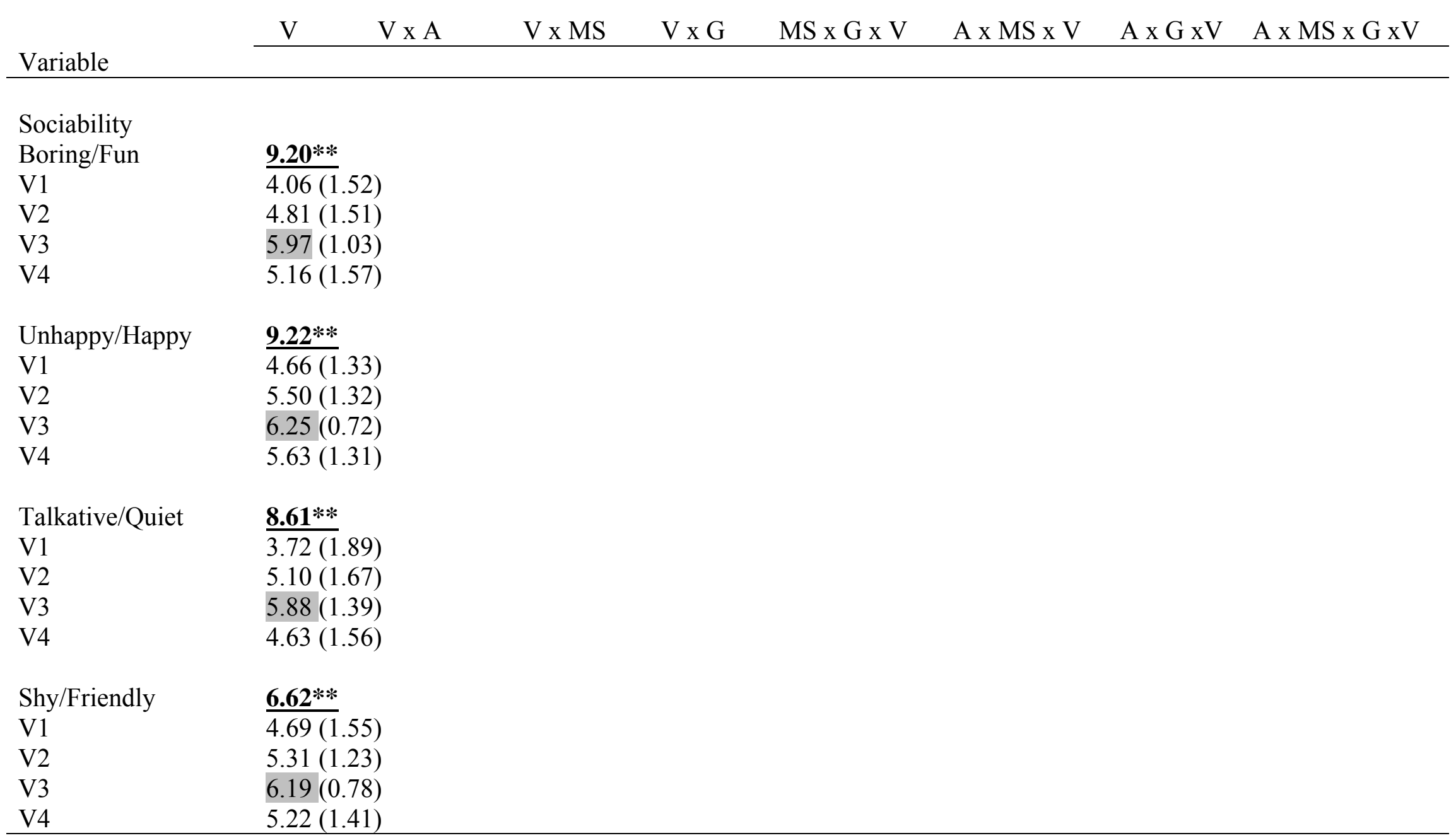


Table 13 (continued)

F-statistics, Means, and Standard Deviations for Significant Individual Items in the MRS with Video Effects

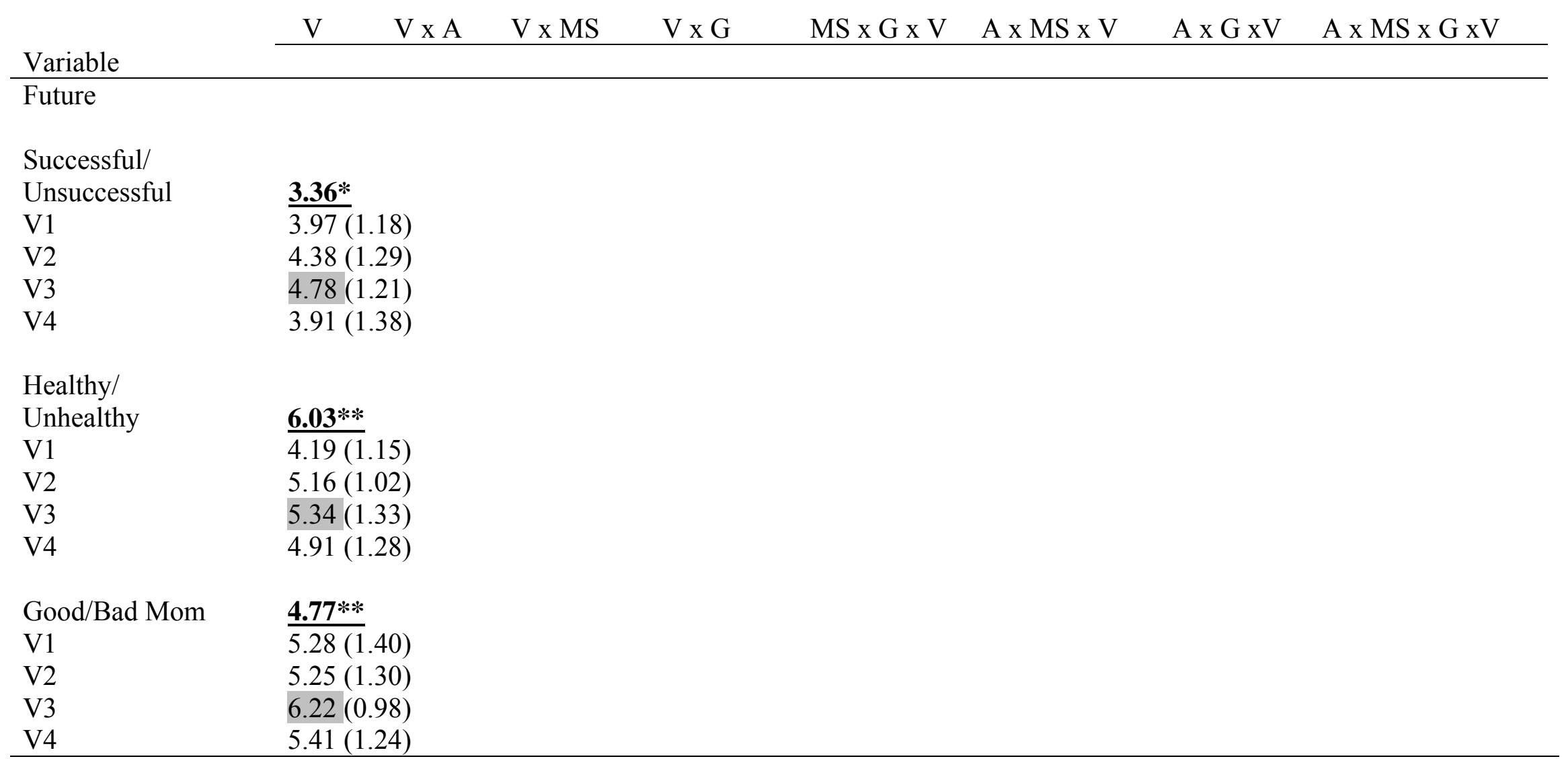

Note. $\mathrm{A}=$ Age Label, $\mathrm{MS}=$ Marital Status Label, $\mathrm{G}=$ Participant Sex, $\mathrm{V}=$ Video Number.

$F$ statistics are in bold and are underlined. Means are followed by standard deviations in parentheses. Highlighted means in each comparison indicate more positive ratings. When no mean in a comparison is highlighted, the means are equal.

$* p<.05, * * p<.01$. 
Table 14

F-statistics, Means, and Standard Deviations for Significant Individual Items in the IIRS with Video Effects

\begin{tabular}{|c|c|c|c|c|c|c|c|}
\hline \multirow[b]{2}{*}{ Variable } & $\mathrm{V} \times \mathrm{A}$ & $\mathrm{V} \times \mathrm{MS}$ & $\mathrm{V} \times \mathrm{G}$ & $M S \times G \times V$ & $\mathrm{~A} \times \mathrm{MS} \times \mathrm{V}$ & $A \times G \times V$ & $\mathrm{~A} \times \mathrm{MS} \times \mathrm{G} \times \mathrm{V}$ \\
\hline & & & & & & & \\
\hline \multicolumn{8}{|l|}{ Overall } \\
\hline Attention to Mom & $9.34 * *$ & & & & & & \\
\hline V1 & $\overline{5.09(1.44)}$ & & & & & & \\
\hline $\mathrm{V} 2$ & $4.41(1.56)$ & & & & & & \\
\hline Facial Expression & $\underline{45.43 * *}$ & & & & & & \\
\hline $\mathrm{V} 1$ & $\overline{5.03(1.31)}$ & & & & & & \\
\hline $\mathrm{V} 2$ & $3.88(1.36)$ & & & & & & \\
\hline V3 & $6.63(0.61)$ & & & & & & \\
\hline $\mathrm{V} 2$ & $4.75(1.34)$ & & & & & & \\
\hline $\mathrm{V} 3$ & $6.63(0.66)$ & & & & & & \\
\hline V4 & $5.75(1.24)$ & & & & & & \\
\hline Fussiness & $\underline{48.10 * *}$ & & & & & & \\
\hline $\mathrm{V} 1$ & $\overline{6.00(1.24)}$ & & & & & & \\
\hline $\mathrm{V} 2$ & $3.34(1.38)$ & & & & & & \\
\hline V3 & $6.44(0.95)$ & & & & & & \\
\hline V4 & $6.22(1.36)$ & & & & & & \\
\hline
\end{tabular}


Table 14 (continued)

F-statistics, Means, and Standard Deviations for Significant Individual Items in the IIRS with Video Effects

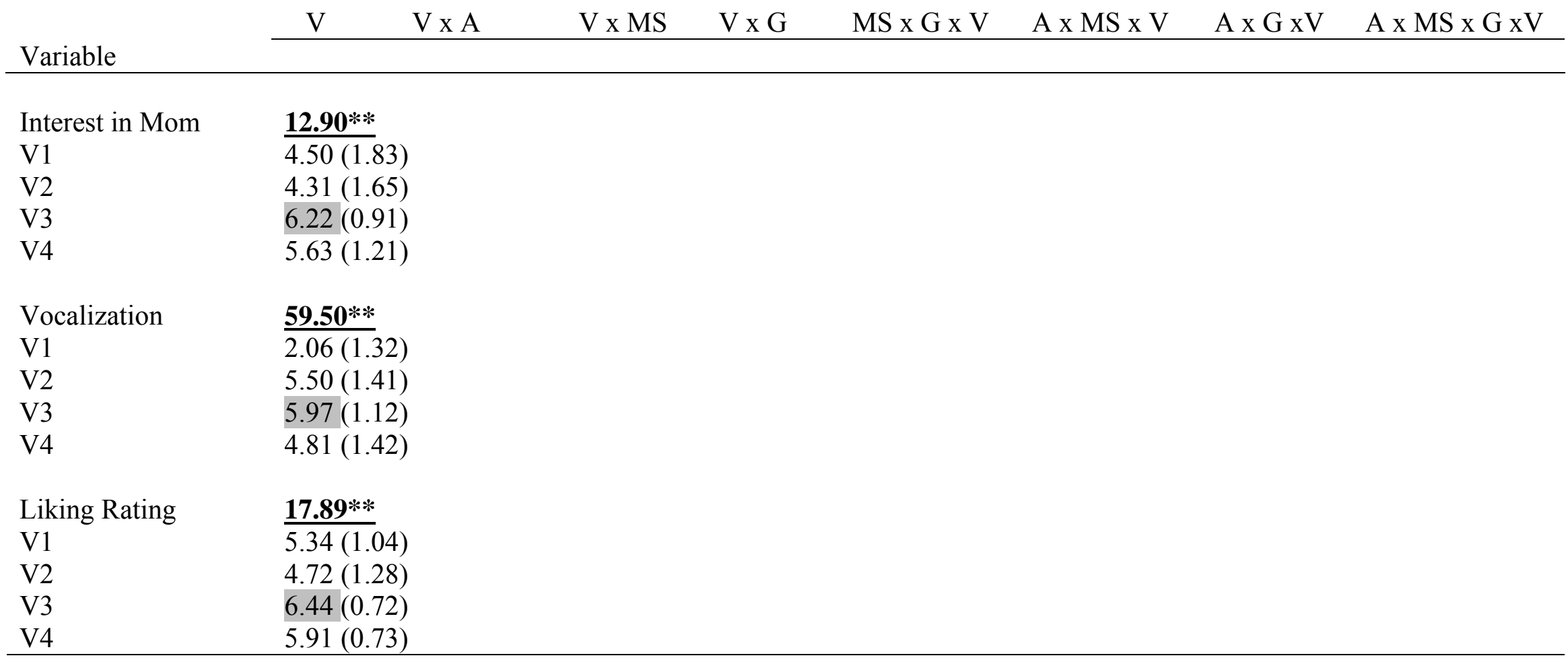

Note. $\mathrm{A}=$ Age Label, MS= Marital Status Label, $\mathrm{G}=$ Participant Sex, $\mathrm{V}=$ Video Number.

$F$ statistics are in bold and are underlined. Means are followed by standard deviations in parentheses. Highlighted means in each comparison indicate more positive ratings. When no mean in a comparison is highlighted, the means are equal.

$* p<.05, * * p<.01$ 


\section{Table 15}

F-statistics, Means, and Standard Deviations for Significant Individual Items in the MIRS without Video Effects

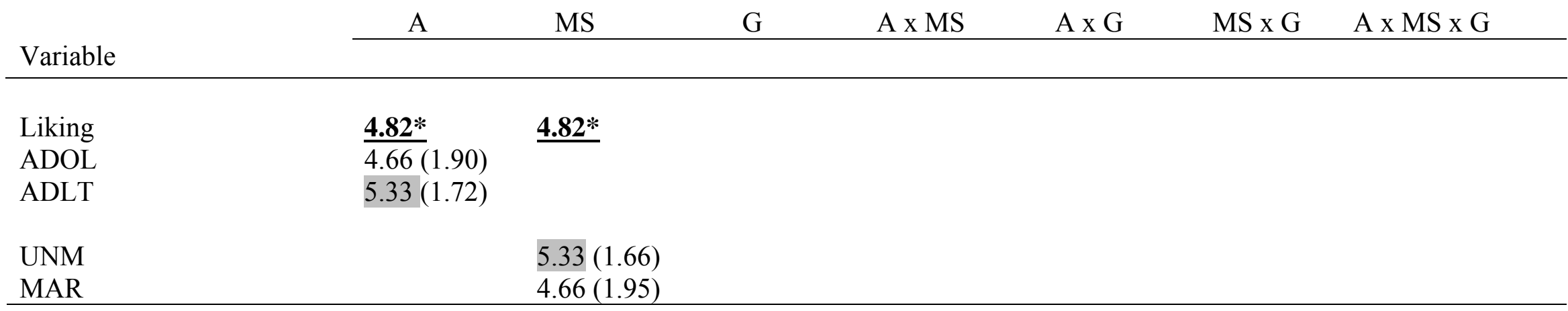

Note. $\mathrm{A}=$ Age Label, MS= Marital Status Label, G= Participant Sex.

$F$ statistics are in bold and are underlined. Means are followed by standard deviations in parentheses. Highlighted numbers in each comparison indicate more positive ratings.

$* p<.05$. 
Table 16

F-statistics, Means, and Standard Deviations for Significant Individual Items in the MIRS with Video Effects

\begin{tabular}{|c|c|c|c|c|c|c|c|}
\hline \multirow[b]{2}{*}{ Variable } & $\mathrm{V} \times \mathrm{A}$ & $\mathrm{V} \times \mathrm{MS}$ & $\mathrm{V} \times \mathrm{G}$ & $\mathrm{MS} \times \mathrm{G} \times \mathrm{V}$ & $\mathrm{A} \times \mathrm{MS} \times \mathrm{V}$ & $A \times G \times V$ & $\mathrm{~A} \times \mathrm{MS} \times \mathrm{G} \times \mathrm{V}$ \\
\hline & & & & & & & \\
\hline \multicolumn{8}{|l|}{ Overall } \\
\hline Responsiveness & 4.94** & & & & & & \\
\hline $\mathrm{V} 1$ & $\overline{5.44(0.95)}$ & & & & & & \\
\hline $\mathrm{V} 2$ & $5.75(1.14)$ & & & & & & \\
\hline Attention to Infant & $3.93^{*}$ & & & & & & \\
\hline V1 & $\overline{5.66(0.97)}$ & & & & & & \\
\hline $\mathrm{V} 2$ & $5.88(1.31)$ & & & & & & \\
\hline V3 & $6.47(0.80)$ & & & & & & \\
\hline $\mathrm{V} 2$ & $5.88(0.98)$ & & & & & & \\
\hline V3 & $6.38(0.79)$ & & & & & & \\
\hline V4 & $5.25(1.27)$ & & & & & & \\
\hline Interest in Infant & $4.50 * *$ & & & & & & \\
\hline V1 & $\overline{5.81(1.09)}$ & & & & & & \\
\hline $\mathrm{V} 2$ & $6.19(0.93)$ & & & & & & \\
\hline V3 & $6.66(0.75)$ & & & & & & \\
\hline V4 & $5.72(1.40)$ & & & & & & \\
\hline
\end{tabular}


Table 16 (continued)

F-statistics, Means, and Standard Deviations for Significant Individual Items in the MIRS with Video Effects

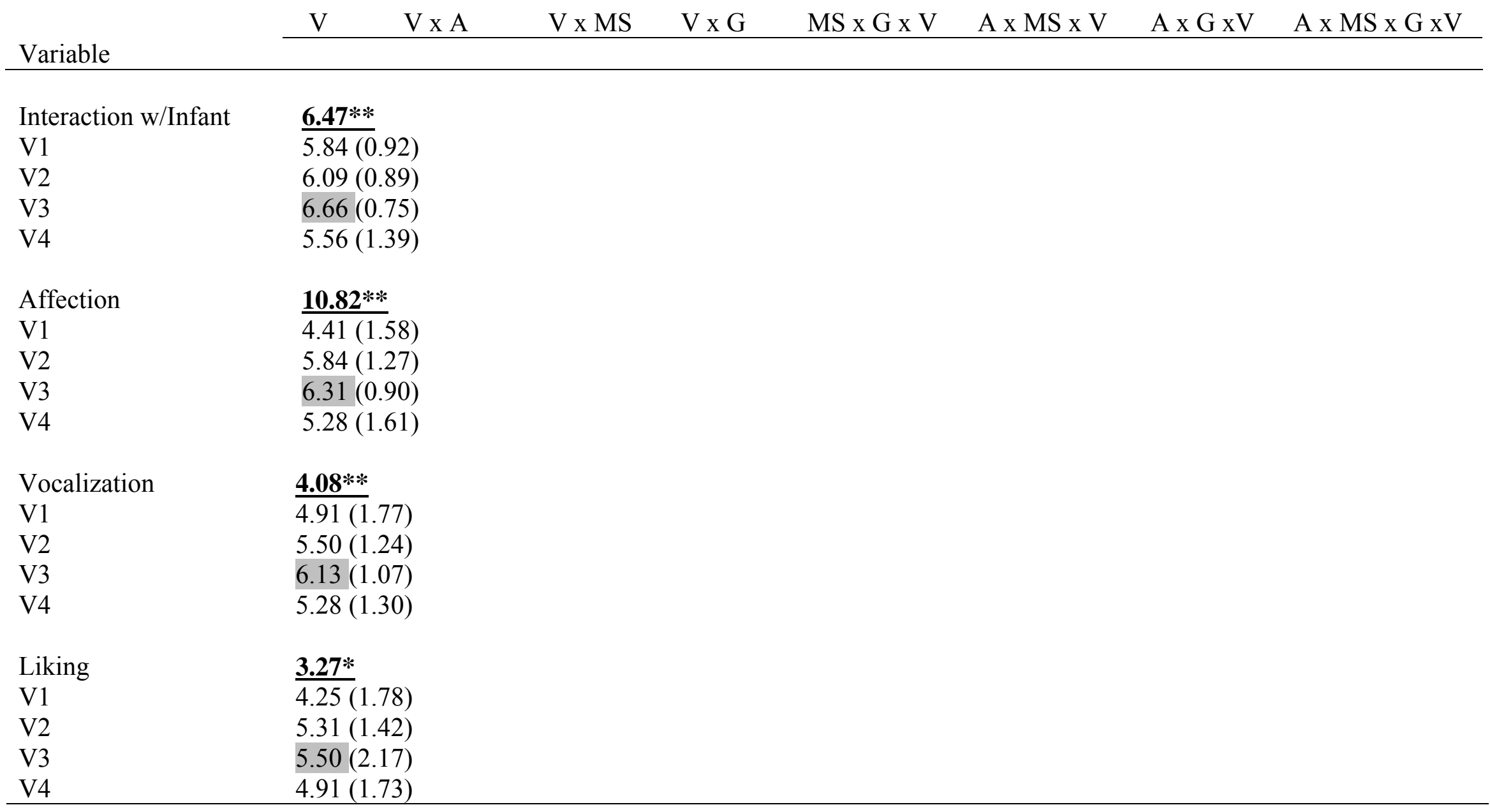

Note. $\mathrm{A}=$ Age Label, $\mathrm{MS}=$ Marital Status Label, $\mathrm{G}=$ Participant Sex, $\mathrm{V}=$ Video Number.

$F$ statistics are in bold and are underlined. Means are followed by standard deviations in parentheses. Highlighted means in each comparison indicate more positive ratings. When no mean in a comparison is highlighted, the means are equal.

$* p<.05,{ }^{* *} p<.01$. 


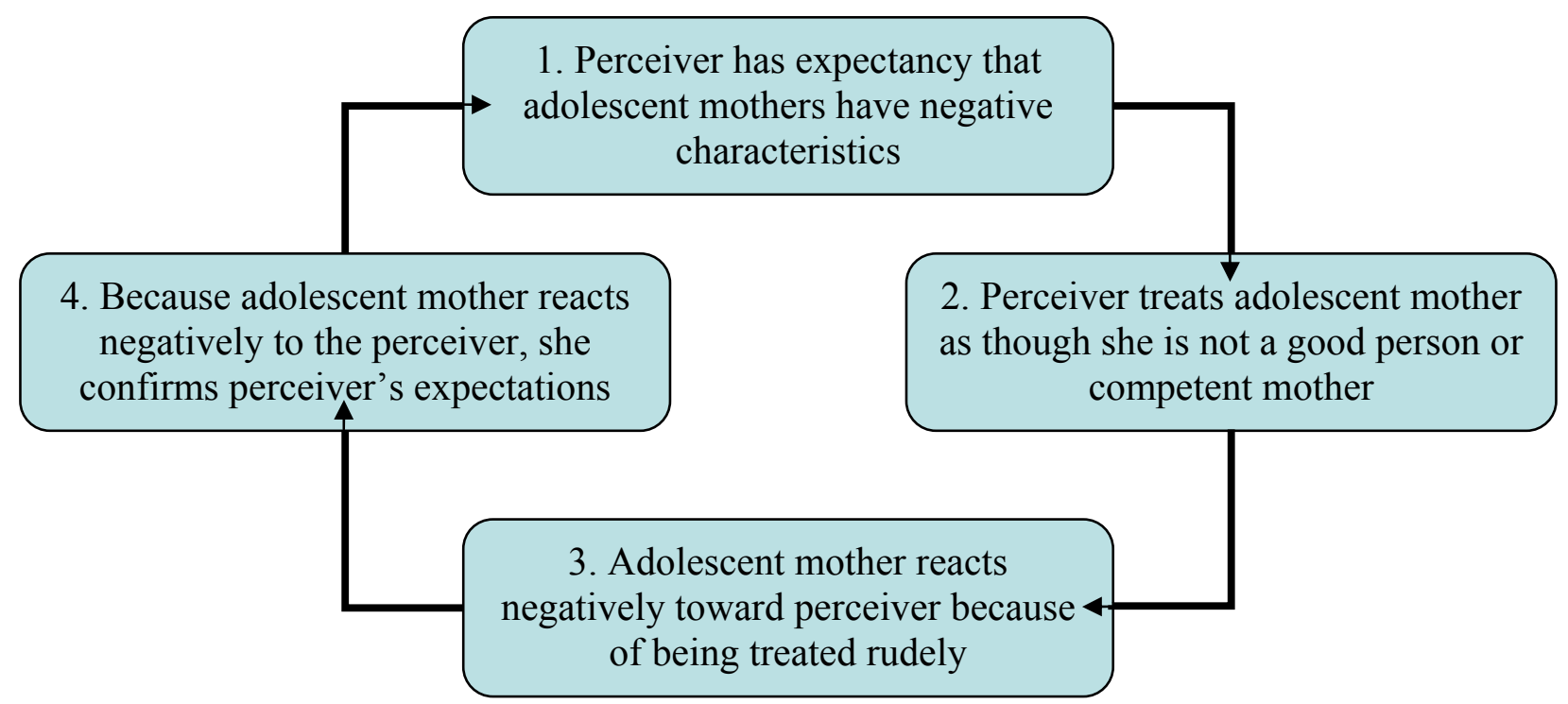

Figure 1: Other's negative expectations of adolescent mothers and the self-fulfilling prophecy model applied to perceptions of adolescent mothers 


\section{Appendix A}

Instructions

The purpose of the present study is to determine how the characteristics of four motherinfant dyads that have had similar experiences compare to one another. During this study you will be viewing four videos, each of a different mother interacting with her infant. Prior to watching these videos, a video focusing on infants at 6 months of age will be shown in order to familiarize you with the behaviors of infants at this age. Before each video you will be asked to read a description about the mother and infant you will be watching next. After each video, you will be asked to fill out three different questionnaires; one will involve questions about the infant, the next will involve questions about the mother, and the third will involve questions about the interaction between the infant and mother. At the end of the study you will be asked to fill out a questionnaire about yourself. Please DO NOT look back at the descriptions of the mothers and infants when answering the questionnaires. Also, please be sure the number indicated on the questionnaires $(1,2,3$, or 4$)$ corresponds with the number of the video you are rating (in order, first, second, third, or fourth). 


\section{Appendix B}

\section{Vignettes}

1. Adolescent/ Married: In the next video you will see a 17-year-old mother interacting with her 6-month-old infant. This infant is the mother's first child. The infant was born healthy at full term and was allowed to go home with the mother a few days later. The mother is not currently in school and is taking care of her infant full time. The mother and infant have lived with the mother's husband, father of the child, since the child was born.

2. Adolescent/ Unmarried: Next you will see a video of a 17-year-old mother interacting with her 6-month-old infant. After the infant's birth at full term, the mother moved into her own home and has lived alone with her infant since. The mother is staying at home full time to care for her infant and is not currently in school. The infant was healthy at birth and has remained healthy. This is the first child born to this mother.

3. Adult/ Married: In this next video you will watch a 25-year-old mother and her 6month-old infant interacting. The mother and her healthy infant live with the mother's husband, father of the infant. This infant is the mother's first child. The mother is not in school at this time and cares for her infant full time.

4. Adult/ Unmarried: In the following video a 25-year-old mother and her 6-month-old infant will be interacting. The infant was born at the hospital at full term; the infant has been healthy since birth. This is the mother's first child. The mother has lived alone with her infant since the infant's birth. The mother cares for the infant full time and is not currently in school. 
Appendix C

\section{Infant Rating Scales}

\section{Video 1: Infant 1}

Please rate the infant you just saw:

\begin{tabular}{|c|c|c|c|c|c|c|c|c|}
\hline 1. Big & 1 & 2 & 3 & 4 & 5 & 6 & 7 & Little \\
\hline 2. Shy & 1 & 2 & 3 & 4 & 5 & 6 & 7 & Friendly \\
\hline 3. Quiet & 1 & 2 & 3 & 4 & 5 & 6 & 7 & Loud \\
\hline 4. Smart & 1 & 2 & 3 & 4 & 5 & 6 & 7 & Dumb \\
\hline 5. Cranky & 1 & 2 & 3 & 4 & 5 & 6 & 7 & Pleasant \\
\hline 6. Strong & 1 & 2 & 3 & 4 & 5 & 6 & 7 & Weak \\
\hline 7. Passive & 1 & 2 & 3 & 4 & 5 & 6 & 7 & Assertive \\
\hline 8. Нарpy & 1 & 2 & 3 & 4 & 5 & 6 & 7 & Sad \\
\hline 9. Well behaved & 1 & 2 & 3 & 4 & 5 & 6 & 7 & Not well behaved \\
\hline 10. Fun to play with & 1 & 2 & 3 & 4 & 5 & 6 & 7 & Not fun to play with \\
\hline 11. Not cuddly & 1 & 2 & 3 & 4 & 5 & 6 & 7 & Cuddly \\
\hline 12. Fine featured & 1 & 2 & 3 & 4 & 5 & 6 & 7 & Large featured \\
\hline 13. Not cute & 1 & 2 & 3 & 4 & 5 & 6 & 7 & Cute/ attractive \\
\hline 14. Curious & 1 & 2 & 3 & 4 & 5 & 6 & 7 & Not curious \\
\hline 15. Uncoordinated & 1 & 2 & 3 & 4 & 5 & 6 & 7 & Coordinated \\
\hline 16. Incompetent & 1 & 2 & 3 & 4 & 5 & 6 & 7 & Competent \\
\hline 17. Mature & 1 & 2 & 3 & 4 & 5 & 6 & 7 & Immature \\
\hline
\end{tabular}

18. Overall, how much do you like this infant?
Not at all
$\begin{array}{lllllll}1 & 2 & 3 & 4 & 5 & 6 & 7\end{array}$
Very much 
19. How typical of an average 6-month-old do you think this infant's behavior was?

$\begin{array}{lllllllll}\text { Not very typical } & 1 & 2 & 3 & 4 & 5 & 6 & 7 & \text { Very typical }\end{array}$

Twenty-five years from now will this child be?

20. Successful

$$
\begin{array}{llllllll}
1 & 2 & 3 & 4 & 5 & 6 & 7 & \text { Unsuccessful }
\end{array}
$$

21. Well-

$\begin{array}{llllllll}1 & 2 & 3 & 4 & 5 & 6 & 7 & \text { Maladjusted }\end{array}$
adjusted

22. Unhappy

$\begin{array}{llllllll}1 & 2 & 3 & 4 & 5 & 6 & 7 & \text { Happy }\end{array}$

23. Single $\begin{array}{llllllll}1 & 2 & 3 & 4 & 5 & 6 & 7 & \text { Dating/Married }\end{array}$

24. Poor

$$
\begin{array}{llllllll}
1 & 2 & 3 & 4 & 5 & 6 & 7 & \text { Financially Stable }
\end{array}
$$

25. What was the age (in months) of the infant you just saw?

Was the infant you just saw (circle one)?:

26. A. Born at full term

B. Born prematurely

27. A. Healthy at birth

B. Not healthy at birth

28. What do you think is the sex of the infant you just saw?
A. Male
B. Female 
Appendix D

\section{Mother Rating Scales}

\section{Video 1: Mother 1}

Please rate the mother you just saw:

\begin{tabular}{|c|c|c|c|c|c|c|c|c|}
\hline 1. Kind & 1 & 2 & 3 & 4 & 5 & 6 & 7 & Unkind \\
\hline 2. Boring & 1 & 2 & 3 & 4 & 5 & 6 & 7 & Fun \\
\hline 3. Careful & 1 & 2 & 3 & 4 & 5 & 6 & 7 & Careless \\
\hline 4. Gentle & 1 & 2 & 3 & 4 & 5 & 6 & 7 & Rough \\
\hline 5. Unhappy & 1 & 2 & 3 & 4 & 5 & 6 & 7 & Happy \\
\hline 6. Intelligent & 1 & 2 & 3 & 4 & 5 & 6 & 7 & Unintelligent \\
\hline 7. Nurturing & 1 & 2 & 3 & 4 & 5 & 6 & 7 & Neglectful \\
\hline 8. Incompetent & 1 & 2 & 3 & 4 & 5 & 6 & 7 & Competent \\
\hline 9. Talkative & 1 & 2 & 3 & 4 & 5 & 6 & 7 & Quiet \\
\hline 10. Mature & 1 & 2 & 3 & 4 & 5 & 6 & 7 & Immature \\
\hline 11. Shy & 1 & 2 & 3 & 4 & 5 & 6 & 7 & Friendly \\
\hline 12. Tired & 1 & 2 & 3 & 4 & 5 & 6 & 7 & Well-rested \\
\hline 13. Well-groomed & 1 & 2 & 3 & 4 & 5 & 6 & 7 & Unkempt \\
\hline 14. Unhealthy & 1 & 2 & 3 & 4 & 5 & 6 & 7 & Healthy \\
\hline 15. Responsive & 1 & 2 & 3 & 4 & 5 & 6 & 7 & Unresponsive \\
\hline 16. Patient & 1 & 2 & 3 & 4 & 5 & 6 & 7 & Impatient \\
\hline 17. Anxious & 1 & 2 & 3 & 4 & 5 & 6 & 7 & Relaxed \\
\hline
\end{tabular}

18. Overall, how much do you like this mother?
Not at all
$\begin{array}{lllllll}1 & 2 & 3 & 4 & 5 & 6 & 7\end{array}$
Very much 
Fifteen years from now will this mother be:

19. Happy

$\begin{array}{lllllll}1 & 2 & 3 & 4 & 5 & 6 & 7\end{array}$

Unhappy

20. Unsuccessful

$\begin{array}{lllllll}1 & 2 & 3 & 4 & 5 & 6 & 7\end{array}$

Successful

21. Healthy

$\begin{array}{lllllll}1 & 2 & 3 & 4 & 5 & 6 & 7\end{array}$

Unhealthy

22. Married

$\begin{array}{lllllll}1 & 2 & 3 & 4 & 5 & 6 & 7\end{array}$

Single/Divorced

23. A good mother

$\begin{array}{lllllll}1 & 2 & 3 & 4 & 5 & 6 & 7\end{array}$

A bad mother

24. What is the age of the mother you just saw?:

Was the mother you just saw (circle one)? :

25. A. Living alone with the infant

B. Living with the infant and a spouse

26. A. In school

B. Not in school/ caring for her infant full time

27. A. A first time mother

B. Already had children before this infant 


\section{Video 1:}

Appendix E

\section{Interaction Rating Scale}

\section{INFANT RATINGS}

1. State Rating
Very Sleepy
$\begin{array}{lllllll}1 & 2 & 3 & 4 & 5 & 6 & 7\end{array}$
Very Alert

2. Physical Activity
Relaxed
$\begin{array}{lllllll}1 & 2 & 3 & 4 & 5 & 6 & 7\end{array}$
Squirming

3. Attention to Mother

$\begin{array}{lllllllll}\text { Not Attentive } & 1 & 2 & 3 & 4 & 5 & 6 & 7 & \text { Very Attentive }\end{array}$

4. Facial Expressions

$\begin{array}{llllllllll}\text { Frequent Cry Face } & 1 & 2 & 3 & 4 & 5 & 6 & 7 & \text { Frequent Smiling }\end{array}$

5. Interaction with Mother
Not Interacting
$\begin{array}{lllllll}1 & 2 & 3 & 4 & 5 & 6 & 7\end{array}$
Very Interactive

6. Fussiness
No Fussing
$\begin{array}{lllllll}1 & 2 & 3 & 4 & 5 & 6 & 7\end{array}$
Frequent Fussing

7. Interest in Mother
Little interest
$\begin{array}{lllllll}1 & 2 & 3 & 4 & 5 & 6 & 7\end{array}$
Very interested

8. Vocalizations

$\begin{array}{llllllllll}\text { No Vocalizations } & 1 & 2 & 3 & 4 & 5 & 6 & 7 & \text { Frequent Vocalizations }\end{array}$

9. Overall Interaction of Infant
Very Negative
$\begin{array}{lllllll}1 & 2 & 3 & 4 & 5 & 6 & 7\end{array}$
Very Positive 


\section{MOTHER RATINGS}

1. State Rating
Very Drowsy
$\begin{array}{lllllll}1 & 2 & 3 & 4 & 5 & 6 & 7\end{array}$
Very Alert

2. Responsiveness to Infant

$\begin{array}{lllllllll}\text { Not Responsive } & 1 & 2 & 3 & 4 & 5 & 6 & 7 & \text { Very Responsive }\end{array}$

3. Attention to Infant
Not Attentive
$\begin{array}{lllllll}1 & 2 & 3 & 4 & 5 & 6 & 7\end{array}$
Very Attentive

4. Facial Expressions

Frequent Sad/Angry
Faces
$\begin{array}{lllllll}1 & 2 & 3 & 4 & 5 & 6 & 7\end{array}$
Frequent Smiling

5. Interest in Infant
Little Interest
$\begin{array}{lllllll}1 & 2 & 3 & 4 & 5 & 6 & 7\end{array}$
Very Interested

6. Interaction with Infant

$\begin{array}{llllllllll}\text { Not Interacting } & 1 & 2 & 3 & 4 & 5 & 6 & 7 & \text { Very Interactive }\end{array}$

7. Affection
No Affection
$\begin{array}{lllllll}1 & 2 & 3 & 4 & 5 & 6 & 7\end{array}$
Very Affectionate

8. Engaging Infant in Play

$\begin{array}{llllllllll}\text { No Engagement } & 1 & 2 & 3 & 4 & 5 & 6 & 7 & \text { Frequent Engagement }\end{array}$

9. Vocalizations

$\begin{array}{llllllllll}\text { No Vocalizations } & 1 & 2 & 3 & 4 & 5 & 6 & 7 & \text { Frequent Vocalizations }\end{array}$

10. Overall Interaction of Mother
Very Positive
$\begin{array}{lllllll}1 & 2 & 3 & 4 & 5 & 6 & 7\end{array}$
Very Negative 


\section{Appendix F \\ Background Information}

1. Sex: Male Female

2. Age:

3. Year in college:

4. Major in college:

5. Ethnic background:
A. African American
B. Asian
C. Hispanic
D. Non-Hispanic White
E. Other:

6. State and county of primary high school attendance:

State:

County:

7. What is your religion?:

8. How religious do you consider yourself?

$\begin{array}{llllllllll}\text { Not religious at all } & 1 & 2 & 3 & 4 & 5 & 6 & 7 & \text { Very religious }\end{array}$

9. Marital Status:
A. Married
B. Not married
C. Cohabitating

If married, number of years you have been married:

10. Do you have any children? Yes No

If yes, what age(s)?:

If no, do you plan to someday have children?
A. Yes
B. No
C. Maybe 
11. During the past year, how frequently have you had contact with infants, on average?
A. At least once a week
B. At least once a month
C. Rarely
D. Not at all

12. How much do you like infants?
A. Much more than average
B. More than average
C. Average
D. Less than average
E. Much less than average

13. Do you have any younger siblings? Yes No

If yes, what age(s)?

14. Have you had any contact with adolescent mothers in the past 5 years? Yes No

If yes, please list (by relationship to you, NOT by name) the adolescent mothers you have had contact with and describe the frequency of that contact below. For example: Cousin, Few times a month.

\section{$\underline{\text { Adolescent Mother } \quad \text { Frequency of contact }}$}

1.

2.

3.

4.

5.

15. Overall, what are your perceptions of adolescent mothers' ability to care for their infants?

$\begin{array}{lllllllll}\text { None } & 1 & 2 & 3 & 4 & 5 & 6 & 7 & \text { A great deal } \\ \text { None } & 1 & 2 & 3 & 4 & 5 & 6 & 7 & \text { A great deal } \\ \text { None } & 1 & 2 & 3 & 4 & 5 & 6 & 7 & \text { A great deal } \\ \text { None } & 1 & 2 & 3 & 4 & 5 & 6 & 7 & \text { A great deal } \\ \text { None } & 1 & 2 & 3 & 4 & 5 & 6 & 7 & \text { A great deal }\end{array}$

.

Not at all competent

\section{$\begin{array}{llllllll}1 & 2 & 3 & 4 & 5 & 6 & 7 & \text { Very competent }\end{array}$}

Thank you for your participation in this study! 


\title{
Nichole L Elliott
}

\author{
Curriculum Vitae
}

$\underline{\text { Professional Address }}$

West Virginia University

Department of Psychology

Life Sciences Building

PO Box 6040

Morgantown, WV 26506

nelliott@mix.wvu.edu $\underline{\text { Home Address }}$

473 Wilson Avenue

Morgantown WV 26508

Phone: (304) 685-3567

\section{Education}

08/02 - Present West Virginia University; Life Span Developmental Psychology Doctoral Program; MA; Ph.D. in progress

Thesis Title: Perceptions of mothers labeled adolescent or adult and their infants.

08/98 - 12/01 The Pennsylvania State University; BA Psychology (Minor: Sociology); Graduation Date 12/01

\section{Scholarships and Awards}

2002 - Present $\quad$ Endowed Doctoral Teaching Fellowship (West Virginia University)

2001 Membership to Golden Key International Honour Society

2000 - $2001 \quad$ Dean's List (Consecutive Semesters; The Pennsylvania State University)

\section{Related Professional Experience}

2002 - Present Teaching Assistantship; West Virginia University

Supervisor: JoNell Strough, Matthew Scullin, Katherine Karraker.

\section{Teaching Experience}

$2002-2004 \quad$ Instructor, Introduction to Human Development, West Virginia University.

Responsible for lecture development and presentation, student grade record maintenance, and exam development and proctoring. 
Instructor, Professional Field Experience, West Virginia University.

Responsible for grading weekly questions, making sure weekly activity reports are fulfilled, grading term papers, student grade record maintenance, and answering email questions about the course.

2004 - present Instructor, Introduction to Social Psychology, West Virginia University.

Responsible for lecture development and presentation, student grade record maintenance, grading term project, and exam question development and proctoring.

\section{Completed Courses}

2005

2004

2004

2004

2004

2004

2003

2003

2003

2003

2003

2002

2002

2002

2002
Ethical and Legal Issues in Psychology

Seminar in Life-span Developmental Psychology: Caregiving Across the Lifespan

Advanced Professional Issues in Developmental Psychology

Developmental Psychology Practicum: Bayley Scales of Infant

Development Training

Program Evaluation/Intervention

Methodological Issues in Developmental Psychology

Multivariate Statistical Analysis

Adult Development and Aging

Child/Adolescent Social Development

Conceptual Issues in Life Span Developmental Psychology

Research Design and Data Analysis II

Child and Adolescent Cognitive Development

Infant Development

Professional Issues in Developmental Psychology

Research Design and Data Analysis I 


\section{Research Interests}

Research interest focus on successful parenting in infancy and early childhood. More specifically, I am interested in perceptions of adolescent mothers and their infants and the differences between adolescent and adult mothers' competence at parenting. Interests also include parental knowledge of child development and the sources of that knowledge, parental social support, parental self-efficacy, and parental stress and burden. I also have some interests in custodial grandparenting and how that impacts the lives of the grandparents (e.g., stress, life satisfaction, burden). 